\title{
The Quiet Ego Scale: Measuring the Compassionate Self-Identity
}

\author{
Heidi A. Wayment · Jack J. Bauer • Kateryna Sylaska
}

Published online: 5 July 2014

(C) The Author(s) 2014. This article is published with open access at Springerlink.com

\begin{abstract}
The quiet ego refers to a self-identity that transcends egoism and identifies with a less defensive, balanced stance toward the self and others. Study 1 establishes and confirms the 14-item Quiet Ego Scale (QES) as a higher-order latent factor (capturing the theoretical intersection of four first-order factors: detached awareness, inclusive identity, perspective taking, and growth). In studies 2-4 we examined the association of QES with 25 psychological constructs. Results demonstrate that QES is related to a wide range of characteristics and suggest that the QES measures an identity that strikes a balance between a strong sense of agency (but not egoism) and a strong concern for the welfare of others. Although QES was correlated with a number of related characteristics (e.g., self-compassion, self-determination, authenticity, self-transcendence), it was a distinct predictor of outcomes such as resilience, coping efficacy, and indices of well-being that could aid investigations of human happiness.
\end{abstract}

Keywords Quiet ego · Self-identity · Transcending self-interest · Egotism · Compassion · Mindfulness · Humility

\section{Introduction}

It is probably safe to say that the conflicts in this world-geopolitically, interculturally, interpersonally, intrapersonally_ do not stem from too much mindfulness, too much

H. A. Wayment $(\bowtie)$

Department of Psychological Sciences, Northern Arizona University, Raul Castro Building, Box 15106, Flagstaff, AZ 86011, USA

e-mail: Heidi.Wayment@nau.edu

\section{J. J. Bauer}

Department of Psychology, University of Dayton, St. Joseph Hall, Room 329, 300 College Park, Dayton, OH 45469, USA

K. Sylaska

Department of Psychology, University of New Hampshire, Conant Hall, 10 Library Way, Durham, NH 03824, USA 
perspective-taking, too much identification with humanity, or too much concern for longterm human development. Indeed it is probably safe to say that conflicts often start and are perpetuated from a lack of such things, from a voice telling us to look out for number one, a voice like a child's screaming for what he or she wants, devoid of a more comprehensive understanding of what he or she needs, how other people's needs and perspectives might conflict with one's own desires, or how to balance such concerns. The difference is that we adults generally do have such understandings and perspectives, even if we do not exhibit them all the time. When we do not, our ego is noisier, clamoring for attention, for others' approval or validation, or for our own self-enhancement or validation. When we do exhibit qualities of human understanding and compassion, our ego is quieter. Further, a compassionate focus helps to create a self-identity that is conducive to well-being (Gilbert 2009).

\subsection{The Quiet Ego as a Less Defensive Stance Toward the Self and Others}

By the term "quiet ego" we mean to convey a subjective stance toward the self and others in which the volume of the ego is turned down so that it might listen to others as well as the self in an effort to approach life more humanely and compassionately. The term quiet ego suggests that the problems of egotism revolve around the ego's screaming for attention. By quiet ego we do not mean a "squashed" or "little" ego. Instead, the quiet ego constructs a self-identity that is neither excessively self-focused nor excessively other-focused-"an identity that incorporates others without losing the self" (Bauer and Wayment 2008, p. 8).

We adopted the term "quiet ego" for a conference and subsequent book that were designed to pull together a wide range of research topics in psychology on the problems of egotism and on the benefits and varieties of transcending it. The qualities of a quiet ego are far-reaching. They include but are not limited to forgiveness (McCullough and vanOyen Witvliet 2002), gratitude (Emmons and McCullough 2004), humility (Tangney 2000; Exline 2008), generativity (McAdams and de St. Aubin 1992), altruism (Batson 2011), interdependence (Rusbult and Van Lange 2002), self-compassion (Neff 2003) and compassionate love (Sprecher and Fehr 2005). Qualities of a quiet ego are included in lists of virtues or character strengths in positive psychology (Peterson and Seligman 2004), although not every positive-psychology topic is a quiet-ego topic. However, in the present studies, rather than compile a list of quiet-ego qualities, we aimed to identify a subjective stance toward the self and others that cuts across those qualities.

\subsection{Why Ego? Which Ego?}

Why use the term "ego"? It has so many meanings and carries much historical baggage in the field of psychology. To give a sense of what we mean by ego (Bauer and Wayment 2008): Sometimes the ego essentially means "self" in the sense of selfesteem, self-confidence, and self-worth, as with terms like a strong, big, wounded, boosted, or deflated ego. We do not mean ego in this sense. Other times the ego is a distinct phenomenon, with little attention paid to the self, as with Freud's (1953) positioning of the ego as the arbiter, defender, and transformer of internal impulses arising from the id and superego. We do not mean "ego" in the psychoanalytic sense. In a third set of definitions, the ego is that which creates the self. The field of social and personality psychology focuses more on the self than on the ego, ever since William James (1890) distinguished the I and the Me. The Me (or "empirical Me") is comprised of the thought contents of the self-conceptions of one's physical and 
material self, one's social self, and one's psychological (or "spiritual" in the terms of his day) self. The ego is the name we ascribe to that which thinks, a hypothesis or transcendental idea that we create simply because we know something is "doing" the thinking, but we cannot point to what or where. However, developmental psychology has a tradition, rooted in Piaget (1970), that focuses on the structure, rather than the content, of thought - on the degree of differentiation and integration of any one content of thought. Drawing Piaget's structural theory of cognitive development into the psychosocial domain, Loevinger's (1976) theory of ego development and Kegan's (1982) theory of the evolving self, each chart stages of complexity and integration by which one frames or structures one's concepts of the self and others. We approach the notion of ego in this way-that the structure or organization of one's concepts of self and others reflects the workings of the ego. However, we also aim to bring the work of social and personality psychology into the fold: We can study the structuring effects of the quiet ego in situations, in persons, and in the development of persons over time. The quiet ego organizes or frames the self and others in ways that facilitates balance between the self and others as well as growth over time.

\subsection{Stances of Balance and Growth}

We have identified balance and growth as two overarching stances that the quiet ego takes toward the self and others over time (Bauer and Wayment 2008). Balance refers to the quiet ego's considering or weighing of the needs, desires, and perspectives of the self and others (e.g., Crocker and Canevello 2008; Rusbult and Van Lange 2002; Wayment and O'Mara 2008). Growth refers to the quiet ego's consideration of the self and others over time (e.g., Erikson 1950; Loevinger 1976). In other words, the study of the quiet ego involves social/situational, personality, and developmental concerns.

As the term balance implies, we do not take the position that self-interest is bad, even though the problems of excessive self-interest, narcissism, and lacking concern for others is well-documented (e.g., Leary 2004; Twenge 2006). Self-interest is essential for survival and even for the flourishing of a mutual relationship-but only when balanced with concern for others. Conversely, too much concern for others (e.g., unmitigated communion; Helgeson and Fritz 1998) can also be a problem. Balance does not involve only concern for the self and others. Balance also refers to positive and negative appraisals of the self and others. One problem of the noisy ego is an excessive tendency to seek positive self-evaluation, that is, toward unwarranted selfenhancement (Cambell and Buffardi 2008). One problem of a squashed ego is an excessive tendency toward negative self-evaluation (Jack 1991; Lutz-Zois et al. 2013). An optimal balance of positive and negative appraisals appears to be conducive toward well-being and adaptation to difficult life events (Bauer and Bonanno 2001; Fredrickson 2013).

Growth is also about time, particularly about how a person develops in an adaptive or otherwise desirable way longitudinally. The noisy ego interferes with such concerns in three ways (Bauer 2008; Wayment and Taylor 1995). First, the noisy ego is characterized by a focus on one's own needs in the immediate moment, at the expense of even one's own self-interest in the longer term. Second, despite the focus on the immediate moment, this focus is directed more at what the present action yields (particularly in terms of enhanced self-image or social status) rather than on the action itself. Third, when the noisy ego is concerned with the longer term, that concern is characterized by a focus on one's material 
or social progress (i.e., increases in wealth or social status) rather than on one's own progress as a developing person, i.e., personal growth (Bauer et al. in press).

Together, these varieties of balance and growth represent the lens or framework through which the quiet ego interprets and evaluates the self and others. Individually and in combination, these forms of balance and growth facilitate a less-defensive view of the self and others - a stance toward psychosocial life fueled less by the need to protect images of status but more by the humanistic, organismic, and eudemonic concerns (see below) for people in their own right and for fostering meaningful actions, relationships, and contributions to others. These latter concerns are more likely to be the purpose of action when the ego is quieter rather than noisier.

\subsection{The Personological Perspective of the Quiet Ego}

The quiet ego has a particular perspective on personhood-that is, a perspective on questions like "What does it mean to be a person?" and "What qualities of personhood are good?" This perspective involves a combination of value orientations-humanistic, organismic, and eudemonic - that steer the ego's framing of the self (or, to use William James's terms, the I's framing of the Me). These perspectives are commonly viewed together in models of personhood, as seen in the personological tradition (Murray 1938) and self-determination theory (Deci and Ryan 2000) as well as frameworks of the "fully functioning person" (Rogers 1961). The humanistic perspective values the full personbalancing objective characteristics as well as subjective experience-as having worth in him- or herself (Bauer et al. in press; Kasser 2003; Kasser and Ryan 1996). The quiet ego is characterized by humanistic concerns-keeping focus on the person as a human whole, not mistaking the whole for mere appearances or status. Organismic concerns value the person as a self-organizing system that develops over time. Commonly the organismic view is fused with humanistic concerns for personhood, creating a humanistic-organismic perspective of personal growth and personality development (e.g., Maslow 1968; Rogers 1961; Deci and Ryan 2000). The quiet ego, by taking an organismic perspective, values the self and others not merely for their products but also for their processes. Finally, eudemonic well-being is concerned on what leads to the good life, including meaningful qualities in life such as wisdom, moral virtue, vitality, or growth (Ryan and Deci 2001; Waterman 2013). Eudaemonists may value pleasure as an important good in life (as Aristotle did). However, they insist that the source or context or purpose of the action that resulted in that pleasure matters at least as much, and typically more so, than the pleasure itself. So it is with the quiet ego, which neither shies away from nor avoids pleasure on moral grounds yet views pleasure (just as it does with wisdom, virtue, etc.) within the context of a fuller notion of personhood.

These views of personhood are consonant with William James's $(1890,1907)$ notion of a pluralistic self or, especially, Murray's (1938) personological model of personhood. Models of the person in five domains (McAdams and Pals 2006), self-concordance (Sheldon 2004), eudemonic growth (Bauer 2008; Bauer and McAdams 2010), and the quiet ego (Wayment and Bauer 2008) are more recent examples of this perspective. Humanistic, organismic, and eudemonic perspectives provide the quiet ego with a stance toward the self and others that focuses on fuller notions of persons, their meaningful actions, and their development rather than exclusively on the more outwardly apparent-and personologically limited-markers of status and capital. 


\subsection{The Quiet Ego Scale: Measuring the Less Defended Self}

Balance and growth, as noted earlier, represent two overarching stances that the quiet ego takes toward the self and others. Here we introduce four facets of psychosocial thinkingthat is, thinking about the self and others as well as thinking about one's actions and interactions - that facilitate a less defensive and more compassionate self-identity. As noted earlier, this kind of thinking about the self and others carries particular orientations of humanistic, organismic, and eudemonic values. But rather than measure those values per se (e.g., Kasser and Ryan 1993, 1996; Huta and Ryan 2010), we have aimed to measure views of self, others, actions, and time that are likely to reflect those values and thus the prosocial characteristics associated with a quiet ego, such as humility, compassion, gratitude, forgiveness, honesty, fairness, care, generativity, and interdependence. The four facets of quiet-ego thinking are inclusive identity, perspective-taking, detached awareness, and growth, and these characteristics facilitate the more-general stances of balance and growth toward the self and others (Bauer and Wayment 2008).

\subsubsection{Balancing the Self and Others}

The first two facets of quiet-ego thinking - inclusive identity and perspective-taking - deal primarily with the quiet ego's balancing of the self and other, although perspective-taking plays an important role in growth as well. Inclusive identity refers to the degree to which one identifies with others, views the self as the same as others, considers oneself to share personal qualities with others, or otherwise to include others within one's sense of psychosocial identity (Aron et al. 1992; Leary et al. 2008). Inclusive identity increases the likelihood of cooperation and decreases the likelihood of self-protective stances toward the other (Montoya and Pittinsky 2011), particularly as one comes to routinely identify with a wider group of others in one's psychosocial development (Erikson 1950). However, inclusive identity does not guarantee the ability to grasp the actual points of view of the other; inclusive identity may ensue for simplistic reasons. The quiet-ego facet of perspective-taking - which involves reflection on others' points of view-provides a criticalthinking counterbalance to the social bonds and acceptance that are facilitated by inclusive identity. Perspective-taking involves an ability to shift attention away from the self (Cassell 2002; Davis 1983), which facilitates not merely compassion but a conceptual understanding of the conditions of those for whom one feels compassion by virtue of inclusive identity.

Detached awareness and growth also play a role in facilitating a stance of balance, particular with regard to positive and negative emotionality. Detached awareness is largely a non-defensive sort of attention, very similar to the concept of mindfulness (Brown and Ryan 2003). By focusing on the immediate moment without preconceived notions of what one should be doing or of ideals about how the moment will turn out (Brown and Ryan 2003), clears a space against defensiveness, allowing one to acknowledge undesirable qualities of oneself or one's actions (Brown et al. 2008). Growth effects a similar kind of acknowledgement by shifting focus from the immediate moment to longer-term, humanistic personal growth. Detached awareness and the subjective concern for growth provide an interesting counterbalance to each other: the first focuses on the immediate moment without regard for the future, whereas the the later focuses on the longer-term processes of the present moment. The reason that they both contribute to a quiet ego has not to do with the temporal breadth of action identification (Vallacher and Wegner 1987) but rather the 
fact that both detached awareness and the concern for growth are focused on processes as they unfold, rather than evaluations of the products that any one action produces.

\subsubsection{Growth in the Self and Others}

Growth serves simultaneously as the quiet ego's stance toward self and others over time as well as one of the four facets of psychosocial thinking through which one interprets actions and the people who do them. As it turns out, concerns for eudemonic growth (e.g., in one's major life goals) predict the subsequent attainment of eudemonic growth, as reflected in increases over time in measures of ego development (Loevinger 1976) and well-being (Diener et al. 2006; Ryff and Singer 1998). Perspective-taking is an essential componentindeed a mechanism - of Loevinger's model of ego development as well as other forms of psychosocial maturity in the structural tradition of human development (e.g., Damon and Hart 1988; Kegan 1982; Piaget 1970). At higher levels of ego development, people routinely think more complexly and integratively about the perspectives of both the self and others, which is a hallmark quality of the quiet ego (Bauer 2008). Detached awareness also facilitates eudemonic growth, perhaps owing to its non-defensive focus on actions and facilitation of flow-like states from which human development naturally follows (Csikszentmihalyi 1993). Importantly, the quiet ego is concerned with growth not only for the self but also for others, as in the phenomena of care and generativity (McAdams 2008).

\subsection{Rationale for the Current Studies}

We believe that creating a quiet ego measure would be beneficial is because it would measure a set of characteristics that reflect a person's readiness to think, feel, and behave in ways that are compassionate in a broad sense: a psychological closeness between the "self" and "other" that reflects an individual's motivation and capability to think in ways that imply an openness and concern for others' welfare in addition to one's own (Keltner 2010). As a middle-level concept, we propose that a measure of "quiet ego" would be optimized if thought of as a latent construct, a relatively abstract idea that cannot be directly measured but rather inferred from what the four quiet ego characteristics have in common (see Bono and Judge 2003 for similar rationale for measurement of core selfevaluations). With this conceptualization, our method for creating and validating a quiet ego measure is fairly straightforward, for many psychological scales that assess each of the quiet ego characteristics we have described already exist. As we have argued previously (Wayment and Bauer 2008), these four quiet-ego characteristics, either individually or collectively, can be cultivated intentionally and act as a catalyst for the emergence of the others. Finally, a quieter ego is not defined by behavior, any more than the ego (or self) itself is a behavior. The relative quietness or noisiness of the ego is a matter of how the individual interprets the self and others-with objective and mindful awareness in a balanced, integrated, compassionate, and growth-oriented manner. Thus, we conceptualize a quiet ego not as a personality trait but as a set of psychosocial skills and abilities that facilitate personal growth (cf. McAdams 2006, about three levels of personality functioning). We had three specific goals with this set of studies. In study 1 , we developed a parsimonious Quiet Ego Scale (QES) based on the conceptual and theoretical description above. In studies 1 and 2, we aimed to validate the QES by examining its relations with psychological measures consistent with a more compassionate and less defensive selfidentity. In studies 3 and 4 we examined the relations between QES and well-being, controlling for theoretically-related constructs. 


\section{Study One}

Our first step in creating a Quiet Ego Scale (QES) was to administer a set of measures, described below, to two samples of undergraduates. In order to be as inclusive as possible, we selected questionnaires that reflected, broadly construed, the types of constructs we considered to reflect quiet ego characteristics and their correlates (Wayment and Bauer 2008).

\subsection{Method}

\subsubsection{Participants}

Participants from our first sample were introductory psychology students from a private university in the Midwestern United States who received course credit for their participation ( $n=303$; females $54 \%$; males: 35; $11 \%$ did not report). Ages ranged from 18 to 52 years, with a mean age of $18.81(S D=2.89)$. The ethnic distribution of the sample was $78.8 \%$ White, $8.2 \%$ Hispanic of Latino, $2.9 \%$ Asian, $3.2 \%$ Black or African American, $2.5 \%$ American Indian or Alaska Native as well as $2.0 \%$ Native Hawaiian or Other Pacific Islander. Participants in our second sample were introductory psychology students from a large state university in the southwestern United States who received course credit for participating in an online questionnaire study ( $n=320$; male: $44 \%$, female: $56 \%)$. Ages ranged from 18 to 51 years, with a mean age of $19.15(S D=2.63)$. The ethnic distribution of the sample was $91.0 \%$ White, $2.5 \%$ Hispanic of Latino, $1 \%$ Asian, $5 \%$ Black or African American, $1 \%$ American Indian or Alaska Native.

\subsection{Measures}

\subsubsection{Mindfulness}

The Mindful Attention Awareness Scale (MAAS; Brown and Ryan 2003) was used to assess the tendency to be aware in the present moment. Coefficient alpha was .88 and .85 in sample 1 and 2, respectively.

\subsubsection{Allo-Inclusive Identity}

The Allo-Inclusive Identity Scale (AI; Leary et al. 2008) was used to assess one's sense of interconnectedness with other people and the natural world. Participants used overlapping Venn Diagrams to describe best their relationship with a person or object described in each question ranging from 1 (two non-overlapping circles-indicates no relationship or connectedness) to 7 (two highly overlapped circles-indicates complete connectedness). Coefficient alphas were .86 and .85 .

\subsubsection{Wisdom}

The Three Dimensional Wisdom Scale (3D-WS; Ardelt 2003) has 39 items and was used to assess affective, cognitive, and reflective forms of wisdom. This scale includes standardized scales including the Perspective Taking and Empathic Concern subscales of Davis' (1983) Interpersonal Reactivity Index. Coefficient alphas were .85 and .83. 


\subsubsection{Psychological Well-Being}

The Ryff Personal Well-Being Scale (PWB; Ryff 1989) is a 54-item measure that was used to assess validated forms of personal well-being. Of the six scales in the measure items from the personal growth subscale were of particular interest. Coefficient alphas were .95 and .96 .

\subsubsection{Humility}

At the time we conducted this study, there was no generally agreed upon measure of humility so six items assessing humility were created for this study by adapting existing theoretical and conceptual definitions of humility (Exline 2008; Tangney 2000). Tangney (2000) lists five key elements of humility: the ability to acknowledge mistakes and shortcomings, openness to perspective and change, an accurate view of the self's strengths, ability to acknowledge and experience life outside the direct consciousness of the self, and the ability to appreciate the worth of all things. Exline (2008) further develops this into a working definition of humility as a non-defensive and unbiased ability to view the self accurately in terms of both strengths and weaknesses. Items were rated on a 5-point scale $(1=I$ do not identify at all with this item; $5=$ I fully identify with this item $)$. The items were "I can reflect on my bad points without making excuses," "I don't mind taking an honest look at myself," "I try to act in non-defensive ways," "All in all, I think I have an even-handed view of myself," "I think it is important to be humble," and "I can reflect on my good points without feeling overly special." Cronbach alphas for these items were .78 and .69.

\subsubsection{Self-compassion}

The Self-Compassion Scale (SCS; Neff 2003) was used to assess one's kind and understanding view toward the self and experiences. The 26 items reflect six subscales: selfkindness, self-judgment, common humanity, isolation, mindfulness, and over-identification. Coefficient alphas were .91 and .94 .

\subsubsection{Generativity}

The Loyola Generativity Scale (LGS; McAdams and de St. Aubin 1992) was used to assess the one's beliefs, behavior, and future goals in relation to others, coupled with a sense of productivity and advancement (e.g., a sense of "giving back"). Coefficient alphas were .85 and .88 .

\subsubsection{Savoring}

The Savoring Beliefs Inventory (SBI; Bryant 2003) was used to assess one's ability to perceive and experience joy within the moment of a positive event. We used the sevenitem Savoring the Moment Subscale. Coefficient alphas were .86 and .82.

\subsubsection{Self-esteem}

Rosenberg's Self Esteem Scale (RSE; Rosenberg 1965) is a widely-used and validated measure of self-esteem. Respondents rated 10 items using a modified 5-point (from the 
original 4-point) Likert scale ( $1=$ strongly disagree; $5=$ strongly agree $)$. Coefficient alphas were .91 and .89 .

\subsubsection{Self-determination}

The Self-Determination Scale (SDS; Sheldon 1995) was used to assess one's awareness of the self and inner drives and emotions as well as feeling a sense of control over one's actions (e.g., autonomy). The 10-item scale consists of two components, perceived choice and awareness of the self. Coefficient alphas were .82 and 80 .

\subsubsection{Personal Growth Initiative}

The Personal Growth Initiative Scale (PGIS: Robitschek 1998) was used to assess one's desire and behavior aimed at developing as a person. Individuals high in PGIS tend to feel confident in their ability to implement changes in their lives to reach their goals. Coefficient alphas were .90 and .88 .

\subsubsection{Meaning in Life}

The Meaning in Life Questionnaire (MLQ; Steger et al. 2006) is a 10-item scale that measures both the presence of meaning in one's life and one's search for meaning. Coefficient alphas for presence and search were .91 and .92 , respectively.

\subsubsection{Background Measures}

Participants were asked to provide basic demographic information including their sex (male or female), age (open ended), and ethnicity.

\subsubsection{Analytic Procedure}

Prior to performing the analyses of interest, we identified single items from all of the study measures to keep in our initial item pool. These items had different response formats, and we selected the items without concern for redundancy (DeVellis 2012). These items were examined for accuracy, missing values, and assumptions of multivariate analyses according to the suggestions presented by Tabachnick and Fidell (2012). Frequency tables for all variables showed that all reported values fell within the possible range of values for each item. Missing values were found for less than three percent of all cases on all variables. Due to the small percentages, cases with missing values were excluded listwise from all analyses (IBM SPSS 19). Three variables had skewness and kurtosis estimations exceeding -1 to 1 . These values were generally within the -2 to 2 range, but one variable had a kurtosis value greater than 3 . These three variables, whose skewness and kurtosis levels fell outside the acceptable range were subjected to a pairwise linearity analysis with normally distributed variables, and were not found to problematically affect the data. No other violations of assumptions were found.

\subsubsection{Selecting Items for Quiet Ego Scale}

The first goal was to determine if Bauer and Wayment's (2008) hypothesized model of quiet ego characteristics (Fig. 1) could be represented by a relatively small number of 


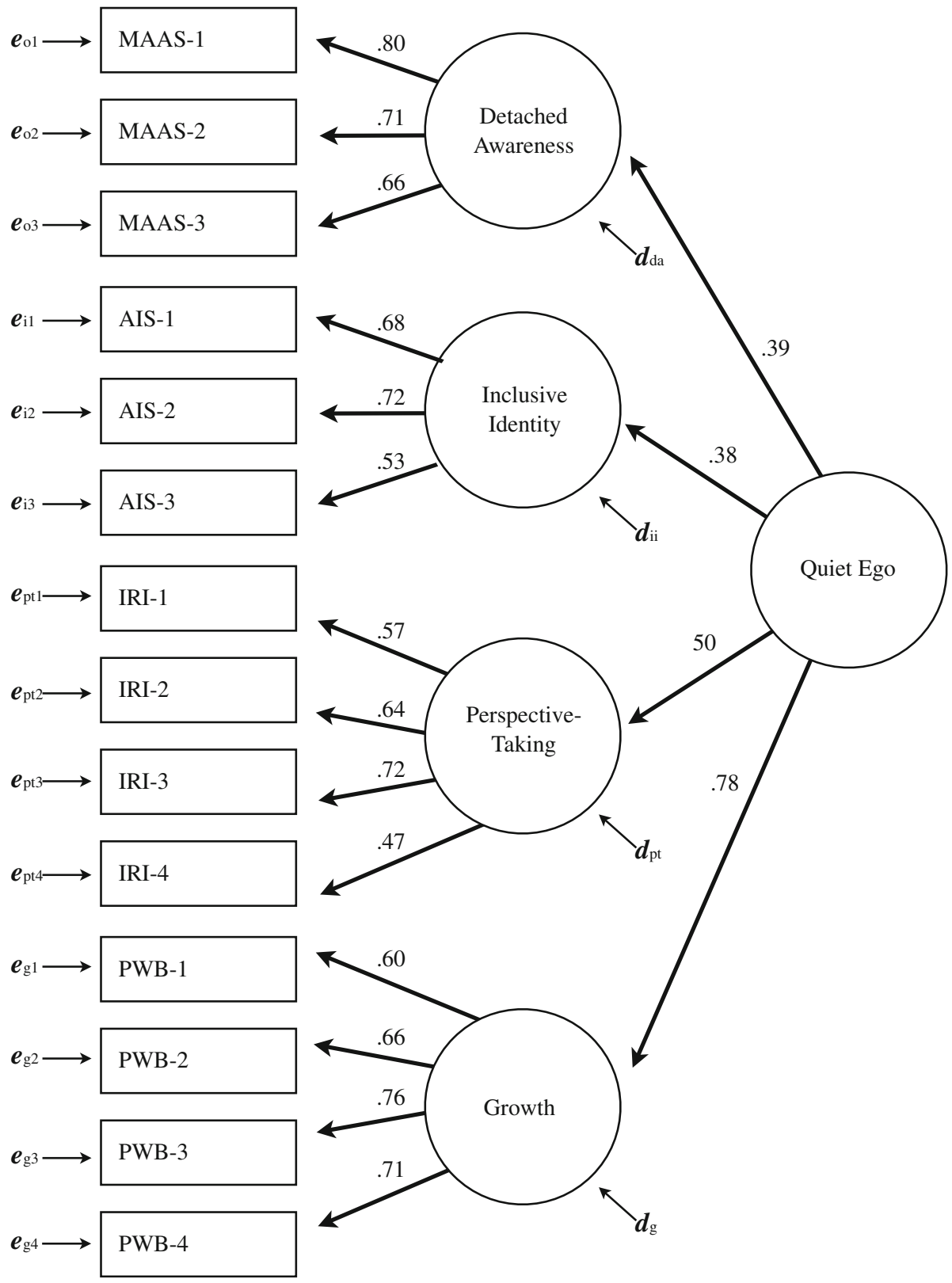

Fig. 1 Factor structure of the Quiet Ego Scale with standardized factor loadings from CFA in sample 2 $(N=330)$. Circles denote latent constructs; rectangles denote measured variables. Paths represent relations among the variables. All factor loadings were significant at $p<.001$

items selected from existing measures. In order to select items that best represented the four sub-factors of the "quiet ego" (as described by Bauer and Wayment 2008), three basic sets of analyses were performed on Sample $1(n=302)$. First, four exploratory factor 
analyses (EFAs) were performed to narrow down a set of scale items selected a priori for each quiet ego sub-factor. Our rationale for evaluating items for each characteristic separately was to provide a context that would allow us to adequately focus on the meaning of each characteristic and not be influenced by the other quiet ego characteristics. Second, a follow-up EFA was conducted with the final set of items derived from the initial EFAs to examine simple structure among the four latent variables. Finally, a confirmatory factor analysis (CFA) was performed using the selected items in a second sample $(n=330)$.

\subsection{Results}

\subsubsection{Exploratory Factor Analyses for QE Sub-Factors}

Four separate EFAs were performed using a promax rotation (IBM SPSS 19). Each EFA was performed on items representing a specific quiet ego sub-factor. An iterative process was used to determine the final selection of items to be included in EFA. Two criteria were used to generate the final item pool: (1) items were available in samples 1 and 2, and (2) items represented, at least on face value, the intent of the quiet ego sub-factor. Initially, "detached awareness" had 11 items, "inclusive identity" had 15 items; "perspective taking" had 12 items, and "growth" had 17 items. All authors of this paper reviewed the items over the period of about one week. The review consisted re-reading the theoretical description in Bauer and Wayment (2008), subsequent discussions, followed by an examination of inter-item correlation matrices and reliabilities. Following this review process, the initial item pools were reduced (detached awareness: 10, inclusive identity: 5, perspective taking: 5, and growth: 9). Table 1 lists the final items selected for the scale. Next, we describe the process whereby the final items were chosen.

For each of the EFAs, factors were selected using a cutoff eigenvalue level of 1.00. Inspection of eigenvalues and scree plots for all of the analyses generally revealed a strong single factor solution. Multi-factor solutions generally revealed a lack of simple structure and failed to meet a minimal criterion of having a primary factor loading of .45 or above in combination with no cross-loading of .30 on any factor. A summary of each of the EFAs will now be described.

\subsubsection{Detached Awareness}

The ten items included in the initial EFA for detached awareness resulted in two factors with eigenvalues above 1.0 (3.34 and 1.51). Due to the lack of simple structure resulting from preserving a two-factor solution and that one factor emerged as much stronger, a one-factor solution was used to determine the detached awareness sub-factor from these ten items. Eight items met the factor loading of .45 or larger cutoff value. In keeping with the goal of developing a short measure, the top three highest loading items were selected. Choosing the top three loadings also allowed all detached awareness items to be taken from a single scale, rather than two different scales. Cronbach's alpha confirmed this three-item solution $(\alpha=.76)$. The final detached awareness items were all from the MAAS (Brown and Ryan 2003).

\subsubsection{Inclusive Identity}

The five inclusive identity items resulted in a two-factor solution to the initial EFA with eigenvalues of 1.89 and 1.54. The decision was made that the second factor, comprised of 
Table 1 Quiet Ego Scale items (in original scale format)

\begin{tabular}{|c|c|}
\hline Subscale & Item \\
\hline \multirow{3}{*}{$\begin{array}{l}\text { Detached } \\
\text { awareness }^{\text {a }}\end{array}$} & I find myself doing things without paying much attention \\
\hline & I do jobs or tasks automatically, without being aware of what I'm doing \\
\hline & I rush through activities without being really attentive to them \\
\hline \multirow{3}{*}{$\begin{array}{l}\text { Inclusive } \\
\text { identity }^{\mathrm{b}}\end{array}$} & The connection between you and all living things \\
\hline & The connection between you and a stranger on a bus \\
\hline & The connection between you and a person of another race \\
\hline \multirow{4}{*}{$\begin{array}{l}\text { Perspective } \\
\text { taking }\end{array}$} & Before criticizing somebody, I try to imagine how I would feel if I were in their place \\
\hline & When I'm upset at someone, I usually try to put myself in his or her shoes for a while \\
\hline & I try to look at everybody's side of a disagreement before I make a decision \\
\hline & I sometimes find it difficult to see things from another person's point of view (reverse) \\
\hline \multirow[t]{5}{*}{ Growth $^{\mathrm{d}}$} & For me, life has been a continuous process of learning, changing, and growth \\
\hline & I have the sense that I have developed a lot as a person over time \\
\hline & $\begin{array}{l}\text { I think it is important to have new experiences that challenge how you think about } \\
\text { yourself and the world }\end{array}$ \\
\hline & When I think about it, I haven't really improved much as a person over the years \\
\hline & For me, life has been a continuous process of learning, changing, and growth \\
\hline
\end{tabular}

\footnotetext{
${ }^{a}$ Mindful Attention and Awareness Scale (Brown and Ryan 2003); 6-point Likert-scale (1 = almost always, 2 = very frequently, $3=$ somewhat frequently, $4=$ somewhat infrequently, $5=$ very infrequently, $6=$ almost never)

b Allo-Inclusive Identity Scale (Leary et al. 2008); 7-point graphic scale $[1=$ no relationship or connectedness (non overlapping circles representing "self" and "other") to $7=$ complete connectedness (overlapping circles representing "self" and "other")]

c Davis Interpersonal Reactivity Scale, Perspective Taking Subscale (Davis 1983); 5-point Likert scale $(1=$ definitely true of myself $; 5=$ not true of myself $)$

d Ryff's Personal Growth Subscale of Well-Being Scale (1989); 6-point Likert scale (1 = strongly disagree $; 2=$ disagree $; 3=$ slightly disagree $; 4=$ slightly agree $; 5=$ agree $; 6=$ strongly agree)
}

two items previously identified as exceeding acceptable skewness and kurtosis values, would be removed and the one-factor solution used. These two items measured level of connectedness toward kin, while the concept of inclusive identity involves a sense of connection to non-kin. Rather than employ a two-factor solution, in which one factor shows deviations from normality, a single-factor solution was selected. This resulted in a three-item solution for inclusive identity. Calculation of Cronbach's alpha confirmed this three-item solution $(\alpha=.66)$ over the five-item solution $(\alpha=.58)$. The final inclusive identity items were all from the A-I Scale (Leary et al. 2008).

\subsubsection{Perspective Taking}

The five items included in the perspective taking EFA created a single factor with an eigenvalue of 2.19. While two of the five items fell below the .45 cutoff, because one of the items was very close to this cutoff (.43), came from the same scale, and measured the presence of the perspective-taking component of compassion when not grounded in a negative situation (as the other three did), the item was retained. Cronbach's alpha confirmed this four-item solution $(\alpha=.68)$, as not markedly different from the three-item 
solution $(\alpha=.69)$. The final perspective items were from the Perspective Taking subscale of Davis' (1983) Interpersonal Reactivity Index.

\subsubsection{Growth}

The nine items were entered into the EFA. While two eigenvalues exceeded 1.0 (3.13 and 1.09), examination of the scree plot only showed strong differentiation of one factor. Four items exceeded the .45 cutoff value and one additional item met the cutoff value. The highest loading four items were from Ryff's Psychological Well-Being scale, while the fifth item was taken from a different scale (Loyola Generativity Scale). Cronbach's alpha confirmed this four-item solution $(\alpha=.78)$, which did not differ for the five-item solution $(\alpha=.78)$. The final growth items were from the personal growth subscale of the Ryff Personal Well-Being Scale (PWB; Ryff 1989).

\subsubsection{EFA for QE Scale}

By using the highest loadings items for each of the sub-factor EFAs, a total of 14 items were retained for one final EFA, using PCA method of extraction and Promax rotation. This EFA successfully identified four hypothesized factors, and met the criteria for simple structure (Thurstone 1947; each item loaded only on one factor). Four factors emerged from the analysis with eigenvalues greater than $1.00(3.47,1.84,1.63$, and 1.54) and corresponded to the four theoretical factors of the quiet ego emerged from the individual exploratory factor analyses explaining a total of $61 \%$ of the variance for the entire set of variables. The first factor (growth) explained $25 \%$ of the variance, with an additional $13 \%$ explained by the second (detached awareness), $12 \%$ by the third (perspective taking), and $11 \%$ by the fourth (inclusive identity). Factor loadings are presented in Table 2.

The internal reliabilities of the four sub-factors were adequate: detached awareness: .76, inclusive identity: .66 perspective taking: .68, growth: .78. Zero order correlations between the first-order factors ranged from .09 (objective awareness with inclusive identity) to .32 (perspective taking with growth). The average correlation was .19, all $p \mathrm{~s}<.05$. Correlations among the first-order latent factors ranged from .14 to .31 , with an average of .26, all $p$ s $<.05$. The standardized coefficient alpha for the 14-item scale was .78. As expected, growth was moderately correlated with detached awareness, inclusive identity, and perspective taking.

\subsubsection{Confirmatory Factor Analysis}

We subjected the14 items found in sample 1 to a confirmatory factor analysis in sample 2 using EQS, using maximum likelihood (ML) method of estimation (Bentler 1995; Hurley et al. 1997). Our hypothesized higher-order model provided a good fit to the data, $\chi^{2}$ $(73)=126.19, p<.001, \chi^{2}: \mathrm{df}=1.73, \mathrm{CFI}=.94, \mathrm{NNFI}=.92, \mathrm{RMSEA}=.05$. All beta coefficients were significant, $p<.001$, and presented in Fig. 1. The standardized coefficient alpha for the 14-item scale was .78. The final items for this scale are listed in Table 1.

\subsubsection{Correlates of QES}

We used data from samples one and two to evaluate initially the validity of the QES by examining its associations with previously validated scales (DeVellis 2012; Worthington and Whittaker 2006). In both samples, QES was unrelated to participant age, gender, or 
Table 2 Factor loadings for exploratory factor analysis

\begin{tabular}{lllll}
\hline Item & Detached awareness & Inclusive identity & Pespective taking & Growth \\
\hline DA 5 & .79 & .16 & .14 & .27 \\
DA 4 & .72 & .11 & .11 & .18 \\
DA 3 & .67 & .04 & .10 & .23 \\
II 6 & .04 & .71 & .11 & .23 \\
II 4 & .14 & .69 & .22 & .13 \\
II 7 & .11 & .54 & .09 & .17 \\
PS 3 & .12 & .14 & .75 & .22 \\
PS 2 & .06 & .19 & .63 & .22 \\
PS 1 & .08 & .08 & .57 & .21 \\
PS 4 & .28 & .17 & .45 & .38 \\
G 15 & .25 & .28 & .27 & .76 \\
G 14 & .18 & .17 & .22 & .73 \\
G 17 & .22 & .20 & .21 & .65 \\
G 16 & .23 & .11 & .27 & .61 \\
\hline
\end{tabular}

ethnic status. Correlations are presented in Table 3. The QES was related most strongly to Humility, Self-Compassion, and the Loyola Generativity Scale. Moderate positive correlations were found between the QES and Savoring Beliefs Inventory, Self-Esteem, SelfDetermination, and Personal Growth Inventory. The QES was associated only weakly with the MLS Presence Subscale (e.g., life is presently meaningful), and not at all with the MLS Searching (e.g., searching for meaning in life).

\subsection{Discussion}

We examined whether Bauer and Wayment's (2008) theoretical conceptualization of the quiet ego as a higher order construct could be demonstrated empirically. Using exploratory and confirmatory analyses, we identified four reliable first-order factors from existing psychological scales in one sample $(n=303)$ and confirmed the factor structure, and replicated the factor structure in a second sample $(n=330)$. The reliability estimates for the subscales and the total scale were acceptable (DeVellis 2012) and reflected the conceptual level (e.g., mid-range theory) of the hypothesized scale. Growth was strongly related to each of the other three quiet ego characteristics and was the highest loading subfactor in our factor analyses, lending support for the importance of growth in our conceptualization of quiet ego. This study also provided evidence that QES was associated with constructs that reflect the overarching themes of balance and growth: humility, selfcompassion, generativity, the ability to savor everyday experiences, having meaning in one's life, well-being, greater self-determination, and more confidence in one's ability to reach one's goals. The QES was unrelated to searching for meaning in life.

\section{Study 2}

Study 1 established a 14-item QES scale based on the theoretical description of the quiet ego (Bauer and Wayment 2008). In order to provide additional information about the 
Table 3 Correlations between QES and psychology measures (Total $N=2,044$ )

\begin{tabular}{|c|c|c|c|c|c|c|}
\hline & \multicolumn{2}{|l|}{ Study 1} & \multicolumn{2}{|l|}{ Study 2} & \multirow[t]{2}{*}{ Study 3} & \multirow[t]{2}{*}{ Study 4} \\
\hline & Sample 1 & Sample 2 & Sample 1 & Sample 2 & & \\
\hline Study $N$ & 303 & 330 & 564 & 209 & 459 & 155 \\
\hline QES (coefficient alpha) & .78 & .78 & .77 & .79 & .76 & .73 \\
\hline Humility $^{\mathrm{a}}$ & $.56 * * *$ & $.57 * * *$ & & & & \\
\hline Self-compassion $^{\mathrm{b}}$ & $.43 * * *$ & $.53 * * *$ & & & $.32 * * *$ & $.36 * * *$ \\
\hline Generativity $^{\mathrm{c}}$ & $.48 * * *$ & $.49 * * *$ & & & & \\
\hline Savoring $^{\mathrm{d}}$ & $.49 * * *$ & $.53 * * *$ & & & & \\
\hline Self-esteem ${ }^{\mathrm{e}}$ & $.45^{* * * *}$ & $.44 * * *$ & & $.43 * * *$ & & \\
\hline Self-determination $^{\mathrm{f}}$ & $.44 * * *$ & $.40 * * *$ & & & & \\
\hline Growth initiative $\mathrm{g}^{\mathrm{g}}$ & $.47 * * *$ & $.42 * * *$ & & & & \\
\hline Presence of meaning $^{\mathrm{h}}$ & $.52 * * *$ & $.32 * * *$ & & & & \\
\hline Search for meaning & -.06 & .07 & & & & \\
\hline Holistic thinking: causality ${ }^{\mathrm{i}}$ & & & $.25^{* *}$ & & & \\
\hline Holistic thinking: attitudes & & & $.20 * *$ & & & \\
\hline \multicolumn{7}{|l|}{ Toward contradictions } \\
\hline Negative thinking ${ }^{\mathrm{j}}$ & & & $-.12 *$ & & & \\
\hline Extraversion $^{\mathrm{k}}$ & & & $.38 * * *$ & & & \\
\hline Conscientiousness & & & $.14 * *$ & & & \\
\hline Openness to experience & & & $.27 * *$ & & & \\
\hline Honesty-humility & & & $.22 * *$ & & & \\
\hline Emotionality & & & -.015 & & & \\
\hline Agreeableness & & & $.33 * * *$ & & & \\
\hline Autonomy ${ }^{1}$ & & & $.25 * *$ & & & \\
\hline Competence & & & $.28 * * *$ & & & \\
\hline Relatedness & & & $.37 * * *$ & & & \\
\hline Physical aggression $^{\mathrm{m}}$ & & & $-.21 * *$ & & & \\
\hline Verbal aggression & & & $-.14 * *$ & & & \\
\hline Anger & & & $-.27 * * *$ & & & \\
\hline Hostility & & & $-.26 * * *$ & & & \\
\hline Cognitive reappraisal $^{\mathrm{n}}$ & & & $.23 * * *$ & & & \\
\hline Expressive suppression & & & $-.11 *$ & & & \\
\hline Psychological entitlement $^{\mathrm{o}}$ & & & $-.12 *$ & & & \\
\hline Youth assets ${ }^{\mathrm{p}}$ & & & & $.39 * * *$ & & \\
\hline Risk taking: psychological ${ }^{\mathrm{q}}$ & & & & $-.24 * * *$ & & \\
\hline Risk taking: physical & & & & .06 & & \\
\hline Self-Transcendence Scale (Reed) ${ }^{\mathrm{r}}$ & & & & & $.44 * * *$ & \\
\hline Self-Transcendence Scale (Levenson) ${ }^{\mathrm{s}}$ & & & & & $.47 * * *$ & \\
\hline Pro-environmental attitudes ${ }^{\mathrm{t}}$ & & & & & $.35^{* * * *}$ & \\
\hline Affect balance ${ }^{\mathrm{u}}$ & & & & & $40 * * *$ & \\
\hline Life satisfaction ${ }^{\mathrm{v}}$ & & & & & $.28 * * *$ & $.24 * *$ \\
\hline Resilience: commitment ${ }^{\mathrm{w}}$ & & & & & & $.40 * * *$ \\
\hline Resilience: control & & & & & & $.35 * * *$ \\
\hline Resilience: challenge & & & & & & $.35 * * *$ \\
\hline
\end{tabular}


Table 3 continued

\begin{tabular}{|c|c|c|c|c|c|c|}
\hline & \multicolumn{2}{|l|}{ Study 1} & \multicolumn{2}{|l|}{ Study 2} & \multirow[t]{2}{*}{ Study 3} & \multirow[t]{2}{*}{ Study 4} \\
\hline & Sample 1 & Sample 2 & Sample 1 & Sample 2 & & \\
\hline Coping self-efficacy ${ }^{\mathrm{x}}$ & & & & & & $.35^{* * *}$ \\
\hline Authenticity ${ }^{\mathrm{y}}$ & & & & & & $.52 * * *$ \\
\hline Five facet mindfulness & & & & & & $.26^{* *}$ \\
\hline Observing $^{z}$ & & & & & & $.27 * *$ \\
\hline Describing & & & & & & $.33 * * *$ \\
\hline Act with awareness & & & & & & .12 \\
\hline Non-judging of inner experience & & & & & & $.20 * *$ \\
\hline Non-reacting to inner experience & & & & & & \\
\hline
\end{tabular}

Strength of correlations (reference): small (.10-.29), medium (.30-.49), large (>.50); Cohen (1992)

${ }^{\mathrm{a}}$ Scale created for this study; ${ }^{\mathrm{b}}$ Self-compassion (Neff 2003); ${ }^{\mathrm{c}}$ Loyola Generativity Scale (McAdams and

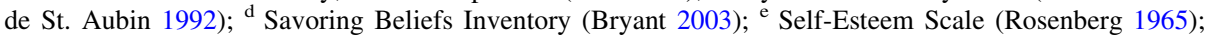
${ }^{\mathrm{f}}$ Self-Determination Scale (Sheldon 1995); ${ }^{\mathrm{g}}$ Personal Growth Initiative Scale (Robitschek 1998); ${ }^{\mathrm{h}}$ MLQ: Meaning in Life Questionnaire (Steger et al. 2006); ${ }^{\text {i }}$ A-HS: Analysis-Holism Scale (Choi et al. 2007); ${ }^{\mathrm{j}}$ Habit Index of Negative Thinking (Verplanken et al. 2007); ${ }^{\mathrm{k}}$ HPI-R: Hexaco Personality InventoryRevised (HPI-R; Ashton and Lee 2009); ${ }^{1}$ BPNS: Basic Psychological Needs Scale (BPNS; Deci and Ryan 2000); ${ }^{\mathrm{m}}$ BPAQ: Buss and Perry Aggression Questionnaire (Buss and Perry 1992); ${ }^{\mathrm{n}}$ ERQ: Emotional Regulation Questionnaire (Gross and John 2003). ${ }^{\circ}$ Psychological Entitlement Scale (Campbell et al. 2004); ${ }^{\mathrm{p}}$ Youth Assets (Oman et al. 2002); ${ }^{\mathrm{q}}$ ATR: Attitudes Towards Risk Scale (Franken et al. 1992); ${ }^{\mathrm{r}}$ SelfTranscendence Scale (STS; Reed 2003; updated 2012); ${ }^{\mathrm{s}}$ The Adult Self-Transcendence Scale (ASTS; Levenson et al. 2005); ${ }^{\mathrm{t}}$ New Ecological Paradigm Scale (Dunlap et al. 2000); ${ }^{\mathrm{u}}$ Affects Balance Scale (Watson et al. 1988); ${ }^{v}$ Satisfaction with Life Scale (SWLS; Diener et al. 1985); ${ }^{\text {w }}$ Dispositional Resilience Scale (DRS; Bartone 2007). ${ }^{\mathrm{x}}$ The Coping Self-Efficacy Scale (CSES; Chesney et al. 2006); ${ }^{\mathrm{y}}$ Authenticity Inventory (AI-3; Kernis and Goldman 2006); ${ }^{\mathrm{z}}$ Five Facet Mindfulness Scale (FFMS; Baer et al. 2006)

$* p<.05 ; * * p<.01 ; * * * p<.001$

convergent validity of the QES we collected data from two additional college student samples, including the QES and 11 self-report measures of personality, individual differences, attitudes, affect, and behavior. We selected variables that we expected would be positively and negatively associated with quiet ego characteristics. Given our assumption that QES represents a less defended and more compassionate self-identity, we expected that QES would be related to an orientation toward psychological growth as reflected in self-determination, prosocial thoughts and behavior, less psychological entitlement, less risk taking, and balance as reflected in more honesty-humility, holistic and cooperative thinking, adaptive coping, less negative thinking, and less aggressive thoughts and behavior. Although we ventured no predictions, we also examined correlations between QES and Hexaco Personality Inventory. In our second sample we included a measure of self-esteem in order to examine its relationship with QES.

\subsection{Method}

\subsubsection{Participants}

The first sample consisted of 564 college students (22\% male, $72 \%$ female; $8 \%$ did not report) who completed online questionnaires for course credit. Ages ranged from 18 to 51 years, with a mean age of $19.38(S D=3.25)$. The ethnic distribution of the sample was $67.0 \%$ White, $13.4 \%$ Hispanic of Latino, $3.8 \%$ Asian, $3.1 \%$ Black or African American, 
$1.5 \%$ American Indian or Alaska Native as well as $2.4 \%$ Native Hawaiian or Other Pacific Islander. The second sample consisted of 209 college students (26\% men, $74 \%$ women). Ages ranged from 18 to 54 years, with a mean age of $20.08(S D=4.09)$. The ethnic distribution of the sample was 71.0\% White, $13.0 \%$ Hispanic of Latino, $6.3 \%$ Asian, $3.9 \%$ Black or African American, $2.4 \%$ American Indian or Alaska Native as well as $2.4 \%$ Native Hawaiian or Other Pacific Islander.

\subsection{Measures}

\subsubsection{Quiet Ego Characteristics (Samples 1 and 2)}

In the first sample the Quiet Ego Scale consisted of 14 items described in Study 1 using the original response scales (5-, 6-, or 7-point scales; see Table 1). Prior to taking the sum of items, scores were standardized $(M=.00, S D=1.00)$. Coefficient alpha was .77 . In sample one, reliabilities for the quiet ego characteristic subscales were as follows (detached awareness: .81, inclusive identity: .62, perspective taking: .73, growth: .87) and the subscale intercorrelations were all significant, but modest. As in study 1, growth was positively correlated with detached awareness, $r(564)=.20, p<.0001$, inclusive identity, $r(564)=.17, p<.0001$, and perspective taking, $r(564)=.21, p<.0001$. Detached awareness was correlated with inclusive identity, $r(564)=.12, p<.01)$ and perspective taking, $r(564)=.12, p<.01)$. Inclusive identity and perspective taking were also correlated, $r(564)=.25, p<.0001$. In this data set the correlations for men $(n=130)$ were positive for all (inclusive identity and detached awareness was $.25 p<.004$ ), but for women it was .08). In the second sample participants answered all questions on a 5-point scale $(1=$ strongly disagree; $5=$ strongly agree). Coefficient alpha was .79 . In the Appendix, we present the items as reformatted for use with a standardized 5-point scale. In sample two, reliabilities for the quiet ego characteristic subscales were as follows (detached awareness: .79, inclusive identity: .56, perspective taking: .75, growth: .83). Again, growth was positively correlated with all three other subscales: detached awareness, $r(209)=.22, p<.001$, inclusive identity, $r(209)=.27, p<.0001$, and perspective taking, $r(209)=.44, p<.0001$. Inclusive identity and perspective taking were strongly related, $r(209)=.42, p<.0001$. Detached awareness was fairly unrelated to inclusive identity, $r(209)=.01$, and only modestly related to perspective taking, $r(209)=.07$. Higher scores on this measure indicate a stronger quiet ego.

\subsubsection{Self-esteem (Sample 2)}

Rosenberg's Self Esteem Scale (RSE; Rosenberg 1965) is described in study 1. Coefficient alpha was .92. Higher scores on this measure indicate higher self-esteem.

\subsubsection{Holistic and Cooperative Thinking (Sample 1)}

The Analysis-Holism Scale (A-HS; Choi et al. 2007) assesses two dimensions of thinking. The Causality subscale captures the belief that "everything is connected" whereas the Attitudes Toward Contradictions subscale depicts the person who prefers harmony and moderation. Coefficient alphas were .88 and .80 , respectively. Higher scores on these measures indicate a greater ability to think in a holistic way and greater preference toward harmony, and moderation in thinking. 


\subsubsection{Negative Thinking (Sample 1)}

The Habit Index of Negative Thinking (HINT; Verplanken et al. 2007) consists of 12 items, which represent habitual negative thinking. Negative thinking is associated with low self-esteem, but unrelated to rumination and mindfulness (Verplanken et al. 2007). Coefficient alpha was .82. Higher scores on this measure indicate a greater preference for negative thinking.

\subsubsection{Personality Traits (Sample 1)}

We measured personality traits using the Hexaco Personality Inventory-Revised (HPI-R; Ashton and Lee 2009). The measure is a 60-item scale that assesses six dimensions of personality: Extraversion, Conscientiousness, Openness to Experience, Agreeableness, Conscientiousness, and Honesty-Humility. Coefficient alphas were .80, .78, .78, .78, .79, and .76 respectively.

\subsubsection{Self-determination (Sample 1)}

The Basic Psychological Needs Scale (BPNS; Deci and Ryan 2000) is a 21-item scale that measures the basic tenets of self-determinations and assesses competence, autonomy, and relatedness since they are theorized to be essential for healthy functioning. Coefficient alpha for autonomy was .67, competence .72, and relatedness .85 . Higher scores on this measure greater endorsement of competence, autonomy, and relatedness goals.

\subsubsection{Aggressive Thoughts and Behavior (Sample 1)}

The Buss and Perry Aggression Questionnaire (BPAQ; Buss and Perry 1992) measures four factors, Physical Aggression, Verbal Aggression, Anger, and Hostility using 29 items. Coefficient alphas for the subscales were as follows: physical aggression: .86, verbal aggression: .81, anger: .85 , and hostility: .88. Higher scores on these measures indicate a greater tendency to engage in these aggressive thoughts and behavior.

\subsubsection{Emotional Regulation (Sample 1)}

The Emotional Regulation Questionnaire (ERQ; Gross and John 2003) assesses individual differences in the habitual use of two emotion regulation strategies: cognitive reappraisal and expressive suppression. Coefficient alphas were .87 and .76 , respectively. Higher scores on this measure indicate greater use of cognitive reappraisal and greater suppression of expressive thoughts, respectively.

\subsubsection{Psychological Entitlement (Sample 1)}

The Psychological Entitlement Scale (PES; Campbell et al. 2004) is a nine-item measure with responses measured on a 7 -point scale $(1=$ strong disagreement; $7=$ strong agreement). Coefficient alpha was .88. Higher scores on this measure indicate a stronger sense of psychological entitlement. 


\subsubsection{Youth Assets (Sample 2)}

We used five youth assets from the Youth Asset Scale (Oman et al. 2002): responsible choices, community involvement, cultural respect, good health practice, and use of time with regard to religion. Coefficient alpha for a total score was .84. Higher scores on this total score indicate a stronger profile of youth assets.

\subsubsection{Attitudes Toward Risk (Sample 2)}

The Attitudes Towards Risk Scale (ATR; Franken et al. 1992) is a 20-item scale used to assess attitudes toward two risk behaviors: psychological risks and physical risks. Coefficient alphas were .94 and .93 respectively. Higher scores on this measure indicate a higher preference for risk taking.

\subsection{Results}

For both samples, there were no gender differences on QES. ${ }^{1}$ Correlational results from both samples are presented in Table 3. As expected, QES was positively related to selfesteem, the Honesty-Humility personality trait, cognitive reappraisal, holistic and cooperative thinking, youth assets, and self-determination. Negative correlations were found between the QES and expressive suppression emotional regulation, physical aggression, verbal aggression, anger, hostility, negative thinking, psychological risk taking, and psychological entitlement. QES was unrelated to physical risk taking. We also found small to moderate positive correlations between QES and Extraversion, Conscientiousness, Openness to Experience, and Agreeableness, but no relationship with Emotionality. In order to strengthen conceptual validity for the QES, in our second sample we were able to examine whether the correlations with QES remained significant after controlling for self-esteem. Results indicated that although the strength of the correlations diminished somewhat, all significant findings remained significant (youth assets: $r=.24, p<.001$; psychological risk taking $r=-.14, p<.05)$.

\subsection{Discussion}

Results of Study 2 provide further support that the QES is reliable and associated with a variety of self-report measures of personality, individual differences, attitudes, affect, and behavior that reflect the four quiet ego characteristics. Results from this study provide additional evidence that QES reflects a self-identity that is less egoistic (e.g., humble and less entitled) and firmly oriented toward psychological growth (e.g., self-determination). Our results also suggest that the QES is related to specific skills that would be expected of an individual who is able to be mindful and have the ability to see other perspectives, such as the ability to think in a holistic and cooperative ways, use adaptive coping and selfregulation strategies, and be less likely to think and act in hostile and aggressive ways.

\footnotetext{
${ }^{1}$ Study 1, Sample 1: QES scores were unrelated to participant age, $\mathrm{r}=.09, p=.116$, gender, $t(283)=$ $-1.51, p=.133$, or ethnic status $F(5,270)=1.17, p=.325$. Study 1, Sample 2: QES was unrelated to age, $\mathrm{r}=.01, p=.116$, gender, $t(314)=-2.53, p=.012$, or ethnic status, $F(4,310)=1.40, p=.233$. Study 2 , Sample 1: QES unrelated to gender, $t(580)=-.650, p=.52$. Study 2, Sample 2: QES unrelated to gender, $t(200)=1.32, p=.17$. Study 3: QES related to gender, $t(449)=3.225, p<.001$, with females reporting higher QES scores $(3.60, \mathrm{SD}=.46)$ than males $(3.44, \mathrm{SD}=.48)$. Study 4: QES unrelated to gender, $t(159)=-.647, p=.52$.
} 
Although the QES was not directly related to less physical risk taking, it was positively associated with a measure of developmental assets that included self-regulation, communication, and social skills that are viewed as protective factors have been shown to be associated with less risk taking and increased competence (Oman et al. 2002). We also found small positive correlations between QES and Extraversion, Conscientiousness, Openness to Experience, and Agreeableness. In addition, results from the second sample in Study 2 showed a moderate and expected relationship between the QES and self-esteem. Controlling for self-esteem, the QES remained significantly associated with greater youth assets (e.g., community involvement, responsible choices, cultural respect, good health practices, religious involvement) and with less psychological risk taking.

\section{Study 3}

The QES scale was hypothesized to capture the commonality between four quiet ego characteristics: detached awareness, inclusive identity, perspective taking, and growth. Analyses in studies 1 and 2 provided promising evidence that our 14-item QES measure is associated with self-reported measures consistent with a compassionate self-identity. Our goals for Study 3 were twofold. First, we sought to strengthen construct validity by examining the extent to which the QES was associated with measures of self-transcendence. According to Levenson and colleagues, self-transcendence "is equivalent to wisdom and implies the dissolution of (self-based) obstacles to empathy, understanding, and integrity" (Levenson et al. 2005, p. 129). Reed (2003) also developed a theory of selftranscendence, incorporating clinical, developmental, and nursing theories to issues surrounding successful aging and coping with death. Reed's definition of self-transcendence is "the capacity to expand self-boundaries intrapersonally (toward greater awareness of one's philosophy, values and dreams), interpersonally (to relate to others and one's environment), temporally (to integrate one's past and future in a way that has meaning for the present), and trans personally (to connect with dimensions beyond the typically discernible world)" (Reed 2003, p. 147). More recent notions of self-transcendence are paired with ideas of ecstasy, altered consciousness, and immortality (Haidt 2012). Although the QES does not measure spiritual beliefs or feelings about death, we hypothesized that the QES should be positively related self-transcendence.

We also wished to examine whether QES, a measure of a compassionate identity, would be related to but yet distinct from self-compassion, which is the ability to extend compassion to the self in instances of failure or perceived inadequacy (Neff 2003). Selfcompassion, also shown to be distinct from self-esteem, is associated with reduced selfcriticism, depression, anxiety, and ruminative thought and positively associated with life satisfaction, social connectedness, and emotional resilience (Leary et al. 2007). Thus, a second goal of this study is to document that while the QES should be related to selfcompassion, it should also be uniquely related to self-transcendence. Finally, given the conceptual and expected empirical overlap between QES, self-compassion, and self-transcendence, we examined the relationship of these measures to two measures of personal well-being (life satisfaction, affect balance) and ecological identity. We reasoned that ecological identity or proenvironmental orientation, unlike measures of personal wellbeing, would be a way to tap an individual's commitment to well-being that extends beyond the self to an interest in the well-being of natural and social ecosystems (Thomashow 1996). 


\subsection{Method}

\subsubsection{Participants}

Participants completed an online-survey, prefaced by a brief description of the survey and an informed consent document, and were compensated with course credit. The sample consisted of 459 (69\% female, $26 \%$ male; $5 \%$ did not report) first year college students. The age ranged from 17 to 56 years, with a mean age of $19.97(S D=3.41)$. The ethnic distribution of the sample was $72 \%$ White, $17 \%$ Hispanic or Latino, $4 \%$ Asian, $8 \%$ Black or African American, $5 \%$ Native American, $2 \%$ Pacific Islander.

\subsection{Measures}

\subsubsection{Quiet Ego Characteristics}

The Quiet Ego Scale consisted of the 14 items described in Study 1, with all items answered using a 5-point scale. Coefficient alpha was .76. Reliabilities for the quiet ego characteristic subscales were as follows (detached awareness: .63, inclusive identity: .63, perspective taking: .69, growth: .79). Growth was positively correlated with detached awareness, $r(459)=.12, p<.01$, inclusive identity, $r(459)=.23, p<.0001$, and perspective taking, $r(459)=.45, p<.0001$. Inclusive identity and perspective taking were moderately correlated, $r(469)=.36, p<.0001$. Detached awareness was not positively associated with inclusive identity, $r(459)=-.04$, and only modestly with perspective taking, $r(459)=.07)$. These correlations are nearly identical to those found in Study 2, sample 2. Higher scores on this measure indicate a stronger quiet ego.

\subsubsection{Self-Transcendence}

Two self-transcendence measures were used. The Self-Transcendence Scale (STS; Reed 2003) is a 15-item, unidimensional measure that assesses self-transcendence as a set of characteristics that reflect a matured and spiritual view of life. Coefficient alpha was .90 . The Adult Self-Transcendence Scale (ASTS; Levenson et al. 2005) is a similar scale that asked respondents to rate items "compared to how you were five years ago." Coefficient alpha was .80. These two scales were moderately correlated, $r(465)=.451, p<.0001$. Higher scores on this measure are associated with viewing the self in a more mature and spiritual way.

\subsubsection{Affect Balance}

The Positive and Negative Affect Schedule (PANAS) was used to calculate the score for affect balance (Watson et al. 1988). Participants read and rated 10 items for positive affect (e.g., determined, inspired); and 10 items for negative affect (e.g., upset, hostile). Reliability coefficients for positive affect and negative affect both .90 . An score of subjective well-being was derived from these affect ratings by creating a ratio of the total positive affect items to the total negative affect items. Higher scores on this measure indicate more positive affect. 


\subsubsection{Ecological Identity}

The (NEP-R; Dunlap et al. 2000) measures endorsements of environmental world views and the degree to which people view humans as part of nature rather than separate from nature. Coefficient alpha was .81. Higher scores on this measure indicate a greater endorsement of the belief that humans and nature are interdependent.

\subsubsection{Life Satisfaction}

The Satisfaction With Life Scale (Diener et al. 1985). is a 5-item instrument designed to measure global cognitive judgments of satisfaction with one's life. Coefficient alpha $=.91$. Higher scores on this measure indicate greater life satisfaction.

\subsection{Results}

In our sample, women's scores on the QES were higher than men's scores (see footnote 1).As expected, QES was correlated positively and moderately with affect balance, life satisfaction, with both the Levenson and Reed self-transcendence scales, with self-compassion, and with pro-environmental attitudes. The Levenson and Reed self-transcendent scales were also correlated with affect balance (both $r \mathrm{~s}=.39)$, life satisfaction $(r \mathrm{~s}=.39$ and .47 , respectively), and with pro-environmental attitudes $(r s=.09$ and .11 , respectively).

To test our hypothesis that QES shared important conceptual overlap with self-transcendence measures, controlling for self-compassion, a hierarchical regression analysis was conducted with entering self-compassion on the first step, followed by QES. Results are presented in Table 4 and reveal that QES was a unique predictor of self-transcendence, as was self-compassion. We next regressed the QES, self-compassion, and both selftranscendence variables onto three measures, life satisfaction, subjective well-being (affect balance scale) and ecological identity. Regression results are presented in Table 5. In general, it was clear that QES did not provide unique predictive variance to life satisfaction, a modest amount to subjective well-being, but was the strongest and only predictor of ecological identity.

\subsection{Discussion}

Results from this study provide further evidence of construct validity in that the QES was correlated with self-compassion, it was also uniquely and positively associated with a spiritual sense of self-transcendence. We also examined the relationship between QES and measures of personal well-being and found that only made a modest direct contribution to positive mood as an indicator of subjective well-being. These results suggest that quiet ego characteristics may have an indirect influence on well-being to the extent that they are related to personal characteristics, traits and abilities known to be associated with wellbeing (Diener et al. 2006). However, to the extent that ecological identity taps a desire for well-being that extends beyond the self, the QES was a strong predictor. These results bolster our confidence that QES, as a measure of a compassionate self-identity, taps an important dimension of self-transcendence, is related to, but also distinct from, selfcompassion and is related to a sense of ecological identity whose focus in on harmony and well-being that can be developed by an appreciation of the reciprocal nature of human activity and environmental health. 
Table 4 Hierarchical regression analysis; does QES share conceptual overlap with self-transcendence? (Study $3 ; N=455$ )

\begin{tabular}{lcclcl}
\hline Variable & $B$ & $S E B$ & $\beta$ & $R^{2}$ & $F$ change in $R^{2}$ \\
\hline Reed Self-Transcendence & & & & & \\
Step 1. Self-Compassion & 2.97 & .47 & $.27^{* * *}$ & .15 & $80.85^{* * *}$ \\
Step 2. QES & 5.18 & .62 & $.36^{* * *}$ & .11 & $70.68^{* * *}$ \\
$F(2,464)$ & $81.85^{* * *}$ & & & & \\
Levenson Self-Transcendence & & & & & \\
Step 1. Self-Compassion & .21 & .03 & $.29 * * *$ & .17 & $95.93^{* * *}$ \\
Step 2. QES & .36 & .04 & $.38^{* * *}$ & .13 & $86.69^{* * *}$ \\
$F(2,464)$ & $100.15^{* * *}$ & & & & \\
\hline
\end{tabular}

QES Quiet Ego Scale

$* * * p<.001$

Table 5 Regression analyses: predictors of life satisfaction, affect balance, and pro-environmental attitudes? (Study $3 ; N=455$ )

\begin{tabular}{|c|c|c|c|c|c|c|c|c|c|}
\hline \multirow[t]{2}{*}{ Variable } & \multicolumn{3}{|c|}{ Life satisfaction } & \multicolumn{3}{|c|}{ Affects balance } & \multicolumn{3}{|c|}{ Pro-environmental attitudes } \\
\hline & $B$ & $S E B$ & $\beta$ & $B$ & $S E B$ & $\beta$ & $B$ & $S E B$ & $\beta$ \\
\hline QES & -.113 & .13 & -.04 & .26 & .08 & $.14 * *$ & 7.07 & .89 & $.41 * * *$ \\
\hline $\mathrm{SC}$ & .602 & .10 & $.28 * * *$ & .52 & .06 & $.36 * * *$ & -1.58 & .65 & $-.12 * *$ \\
\hline RST & .060 & .01 & $.31 * * *$ & .04 & .01 & $.28 * * *$ & -.01 & .06 & -.01 \\
\hline LST & .478 & .14 & $.16^{* *}$ & .11 & .09 & .05 & -.95 & .98 & -.05 \\
\hline$F(4,459)$ & \multicolumn{3}{|c|}{$54.26 * * *$, Adj $\mathrm{R}^{2}=.32$} & \multicolumn{3}{|c|}{$77.85^{* * *}$, Adj $\mathrm{R}^{2}=.40$} & \multicolumn{3}{|c|}{$18.32^{* * *}$, Adj $\mathrm{R}^{2}=.13$} \\
\hline
\end{tabular}

SC Self-Compassion Scale, RST Reed Self-transcendence Scale, LST Levenson Self-Transcendence Scale, QES Quiet Ego Scale

$* * p<.01 ; * * * p<.001$

\section{Study 4}

Studies 2 and 3 extended our confidence that the QES reflect a compassionate self-identity. In study 3, we examined the direct effect of QES on both personal and ecological wellbeing. We also determined that QES, as a measure of a compassionate self-identity, was able to add predictive variance to subjective well-being (mood) above and beyond related constructs self-compassion and self-transcendence, and to ecological identity. In our fourth and last study, we repeated our examination of whether QES would be reliably associated with personal well-being, psychological resilience, and coping efficacy in a sample of firstgeneration, primarily minority, and economically disadvantaged college students. As in Studies 2 and 3, we wanted to examine whether the QES could provide additional explanatory variance after controlling for measured constructs that share similar components to the quiet ego construct: self-compassion, authenticity, and five-facet mindfulness. Kernis and Goldman's (2006) authenticity measure assesses awareness and unbiased processing (similar to mindfulness) and contains two additional subscales: authentic behavior and relational orientation. The Five-Faceted Mindfulness scale, associated with well-being (Baer et al. 2006), is a 39-item measure that taps more specific components of 
mindfulness (observing, describing, acting with awareness, nonjudging of inner experience, and nonreactivity to inner experience) than the three MAAS items used in the QES, The overlap between the QES and Neff's self-compassion scale was described in Study 3. Our goal with this study was to examine whether the QES was related to resilience characteristics above and beyond these established and important measures.

\subsection{Method}

\subsubsection{Participants}

Participants were part of a five-week on-campus summer preparation program for new incoming first year students who were either first-generation college students and/or demonstrated financial need. Volunteers from the program read a brief description of the survey, signed informed consent documents, and completed the questionnaire in a large auditorium. The sample consisted of 155 (67\% female, $33 \%$ male) incoming college students. The ages ranged from 18 to 30 years, with a mean age of $18.19(S D=1.67)$. The ethnic distribution of the sample was 39.5\% White, $29.6 \%$ Hispanic or Latino, $6.8 \%$ Asian, $3.7 \%$ Black or African American, $5.6 \%$ American Indian or Alaska Native; $9.3 \%$ listed other or indicated more than one ethnicity. Eighty-six percent were native English speakers.

\subsection{Measures}

\subsubsection{Quiet Ego Characteristics}

QES consists of 14 items that measure four dimensions of quiet ego: detached awareness, inclusive identity, perspective taking, and growth and described in Study 3. Coefficient alpha was .73. Reliabilities for the quiet ego characteristic subscales were as follows (detached awareness: .70, inclusive identity: .47, perspective taking: .57, growth: .60). Growth was positively correlated with detached awareness, $r(155)=.28, p<.0001$, inclusive identity, $r(155)=.21, p<.01$ and perspective taking, $r(155)=.61, p<.0001$. Inclusive identity and perspective taking were correlated, $r(155)=.20, p<.01$. Detached awareness was modestly associated with inclusive identity, $r(469)=.07, p<.05$, but more strongly with perspective-taking, $r(155)=.25, p<.002$. Higher scores on this measure indicate a stronger quiet ego.

\subsubsection{Resilience}

The Dispositional Resilience Scale (DRS; Bartone 2007) assesses the hardy personality style, and includes Commitment, Control, and Challenge subscales. Coefficient alpha was .79. Higher scores on this measure indicate greater resilience.

\subsubsection{Coping Efficacy}

The Coping Self-Efficacy Scale (CSES, Chesney et al. 2006). The Coping Self-Efficacy Scale (CSES) is a 26-item measure of perceived self-efficacy for coping with challenges and threats. An overall CSES score represents three types of coping skills: problemfocused coping, stop unpleasant emotions and thoughts, receiving support from friends and family. Coefficient alpha was .94. Higher scores on this measure indicate a stronger belief in one's coping efficacy. 


\subsubsection{Life Satisfaction}

The Satisfaction with Life Scale (Diener et al. 1985) was used (described in Study 3). Coefficient alpha $=.82$. Higher scores on this measure indicate greater life satisfaction.

\subsubsection{Authenticity}

The Authenticity Inventory (AI-3; Kernis and Goldman 2006) is a 45-item scale that assesses awareness, unbiased processing, authentic behavior and relational orientation. Coefficient alpha for awareness was .80, for unbiased processing .67, for authentic behavior .77, for relational orientation .78 and total score was .79. Higher scores on awareness is associated with greater knowledge of one's motives, feelings, desires, strengths and weaknesses. Higher scores on unbiased processing mean less distortion of one's personal strengths and weaknesses. Higher scores on authentic behavior indicate more value placed on openness and truthfulness in personal relationships.

\subsubsection{Self-Compassion}

The Self-Compassion Scale was used (described in Study 1). Coefficient alpha was .90. Higher scores on this measure indicate greater self-compassion.

\subsubsection{Mindfulness}

The Five Facet Mindfulness Scale (FFMS; Baer et al. (2006) is a 39-item scale that captures five essential elements of mindfulness: observing, describing, acting with awareness, non-judging of inner experience, and non-reactivity to inner experience. Coefficient alphas for observing: .74, describing: .84, acting with awareness: .86 nonjudging of inner experience: .87 and non-reactivity to inner experience: .70. Higher scores each of these subscales is associated with acting each of these way more often.

\subsection{Results}

\subsubsection{Correlations}

As expected, QES was correlated positively and moderately with three resiliency subscales, life satisfaction, and coping efficacy (see Table 3). As in studies 1 and 2, QES was correlated with self-compassion. Using a different mindfulness scale than the one contributing three items to the QES, results indicated moderate correlations with three mindfulness facets, observing, describing, acting with awareness, and small associations with two facets, non-judging of inner experience and non-reactivity to inner experience. Moderate to larger correlations were found between QES and authenticity, life satisfaction, and coping efficacy. Mindfulness, self-compassion, and authenticity were intercorrelated moderately, $r(156)$ range: .332 to .554 , average $r(156)=.448$.

In order to examine the relationship between QES and psychological resources among first generation college students, we examined the relationship of QES to psychological resilience, coping efficacy, and life satisfaction after controlling for conceptually related constructs self-compassion, authenticity, and five-facet mindfulness. Nine separate hierarchical regressions were computed. Each analysis regressed one of three constructs (selfcompassion, mindfulness, authenticity) to one of three outcomes on the first step, followed 
EQS on the second step. Model results are presented in Table 6 and reveal that the QES predicted additional variance in psychological well-being after controlling for self-compassion (7\%), five-facet mindfulness (10\%), and Authenticity (5\%).

\subsection{Discussion}

Results of study 4 indicate that the QES was reliable and modestly associated with a variety of individual difference measures expected to share conceptual and empirical overlap with QES: authenticity, self-compassion, and five-facet mindfulness. In a series of regression analyses, QES provided little to no significant variance for two outcomes (1-2\% additional variance in life satisfaction, 2-3\% additional variance in coping efficacy), but significant additional variance for psychological resilience (10-17\% additional variance) in a sample of "at risk" pre-college students participating in a college readiness program. Thus, we conclude that the relationship of QES to life satisfaction and coping efficacy in this group of students s likely indirect via its associations with skills, abilities, and attitudes. However, QES had a direct and unique impact on psychological resilience in this at risk sample of college students, suggesting a real-world applicability for the usefulness of quiet ego characteristics.

\section{General Discussion}

With this set of four studies we created a measure of a quiet ego from existing psychological measures that reflect four characteristics (detached awareness, inclusive identity, perspective taking, and growth). Our results provide initial evidence that the quiet ego lies at the inferential and theoretical intersection of four characteristics that represent two overarching stances that the quiet ego takes toward the self and others: balance and growth. The QES, a short and readily useable questionnaire was found to have adequate reliability across six study samples and was related to over 25 psychological measures in expected directions that reflect the key components of the quiet ego as described by Bauer and Wayment (2008).

\subsection{Why a Quiet Ego Scale?}

Similar to our own arguments about the benefits of a quiet ego, Gilbert (2009) draws on over 30 years of clinical experience and describes the compassionate mind as being able to think clearly, have better insights about the self and relations with others. Thus, the ability to measure an identity rooted in balance and growth could be useful to research on the benefits of a compassionate mindset. Given the number of existing psychological scales, one might wonder why not simply use the full-length measures to construct a quiet ego latent variable (example Wayment et al. 2011). This approach is certainly feasible but there are potential drawbacks including lengthier questionnaires and the accompanying requirement of a large sample size and more complex analyses. We believe there is an advantage to using a scale that is not only short but also represents a middle-range construct about an individual's motivation and ability to think and behave with understanding and compassion. Individuals with higher QES scores are more likely to be mindful, motivated by humanistic, organismic, and eudemonic growth goals, have an inclusive identity that recognizes mutual interdependence with others and the natural world, and are motivated and able to understand the perspective of others. 
Table 6 Hierarchical regression analyses; does QES predict life satisfaction, coping efficacy, and resilience controlling for self-compassion, authenticity, and five-facet mindfulness? (study $4 ; N=155$ )

\begin{tabular}{|c|c|c|c|c|c|}
\hline Variable & $B$ & $S E B$ & $\beta$ & $R^{2}$ & $F$ change in $R^{2}$ \\
\hline \multicolumn{6}{|l|}{ Life satisfaction } \\
\hline Step 1. Self-Compassion & 3.55 & .84 & $.34 * * *$ & .15 & $26.76 * * *$ \\
\hline Step 2. QES & 1.66 & .99 & $.13 * * *$ & .02 & 2.83 \\
\hline$F(2,149)$ & $14.96 * * *$ & & & & \\
\hline Step 1. Authenticity & .111 & .033 & $.31 * * *$ & .13 & $20.16 * * *$ \\
\hline Step 2. QES & 1.24 & 1.14 & .10 & .01 & 1.2 \\
\hline$F(2,149)$ & $10.69 * * *$ & & & & \\
\hline Step 1. F-F Mindfulness & 2.73 & 1.13 & $.20 * *$ & .07 & $11.51 * *$ \\
\hline Step 2. QES & 2.00 & 1.03 & $.16^{*}$ & .02 & $3.77 *$ \\
\hline$F(2,149)$ & $7.75 * *$ & & & & \\
\hline \multicolumn{6}{|l|}{ Coping efficacy } \\
\hline Step 1. Self-Compassion & 31.13 & 4.45 & $.50 * * *$ & .31 & $66.66 * * *$ \\
\hline Step 2. QES & 10.77 & 5.21 & $.15^{* * *}$ & .02 & $4.27 *$ \\
\hline$F(2,149)$ & $36.21 * * *$ & & & & \\
\hline Step 1. Authenticity & .81 & .19 & $.38 * * *$ & .22 & $37.54 * * *$ \\
\hline Step 2. QES & 11.64 & 6.39 & $.16^{*}$ & .02 & $3.32 *$ \\
\hline$F(2,149)$ & $20.76 * * *$ & & & & \\
\hline Step 1. F-F Mindfulness & 32.94 & 6.26 & $.41 * * *$ & .23 & $44.20 * * *$ \\
\hline Step 2. QES & 13.35 & 5.53 & $.19 * * *$ & .03 & $5.82 * *$ \\
\hline$F(2,149)$ & $25.73 * * *$ & & & & \\
\hline \multicolumn{6}{|l|}{ Psychological resilience } \\
\hline Step 1. Self-Compassion & 2.75 & .69 & $.29 * * *$ & .19 & $34.47 * * *$ \\
\hline Step 2. QES & 4.38 & .80 & $.40 * * *$ & .14 & $29.65 * * *$ \\
\hline$F(2,149)$ & $35.35 * * *$ & & & & \\
\hline Step 1. Authenticity & .07 & .03 & $.22 * *$ & .17 & $28.19 * * *$ \\
\hline Step 2. QES & 3.98 & .92 & $.37 * * *$ & .10 & $18.59 * * *$ \\
\hline$F(2,149)$ & $25.20 * * *$ & & & & \\
\hline Step 1. F-F Mindfulness & 1.47 & .93 & .12 & .08 & $13.79 * * *$ \\
\hline Step 2. QES & 4.88 & .84 & $.45^{* * *}$ & .17 & $33.84 * * *$ \\
\hline$F(2,149)$ & $25.32 * * *$ & & & & \\
\hline
\end{tabular}

SCS Self-Compassion Scale, FFM Five-Facet Mindfulness, AUT Authenticity, QES Quiet Ego Scale $* p<.05 ; * * p<.01 ; * * * p<.001$

\subsection{Convergent Validity}

Relationships between the QES and other scales were explored to identify the placement of the quiet ego construct within the context of other related psychological constructs. Our results provide preliminary evidence that the QES reflects an orientation toward psychological growth and balance, and key components of a compassionate orientation with most of the correlations in the small to medium range. Personal growth loaded highest on the latent quiet ego factor and was consistently positively correlated with each of the other three subscales. Further, the QES was associated with measures that indicated interest in 
personal growth and balance. For example, the QES was positively associated with selfdetermination, which is the tendency to seek personal growth through competence, autonomous action, and social relationships. Correlational results with the QES suggest that it measures an interest in, motivation for, and psychosocial skills and abilities that could facilitate personal growth. The QES also was related to self-transcendence, a type of spiritual growth, as well as with indices of flexible and open-minded thinking and prosocial attitudes and behavior - views and attitudes associated with a compassionate stance toward others.

The QES also was related to constructs related to a balanced view of the self and others, such as self-compassion and humility. The findings regarding self-compassion are especially encouraging because a compassionate self-identity would be expected to related to self-compassion (Gilbert 2009). In study one self-compassion and QES hared between 16 and $25 \%$ of the variance, while in studies three and four about $9 \%$. However, we also found that QES also added unique predictive variance in psychological resilience in at risk college students, to ecological identity, and to self-transcendence, and to a much smaller degree, in life satisfaction and coping efficacy. Taken together, we believe these relationships with self-compassion bolster our view that the QES measures a compassionate self-identity that is related to an ability to extend compassion to the self, but also transcends self-interest and reflects a balanced concern for self and others. The QES was also related to measures of humility, which reflects a non-defensive and unbiased ability to view the self accurately in terms of both strengths and weaknesses (Exline 2008). In fact, recent experimental research argues that humility acts as an ego quieting mechanism (Kesebir 2014). Future research would benefit from continued examination of the relationship between QES and the types of thoughts, feelings, and behavior expected to more likely with those with compassionate self-identities.

\subsection{QES and Well-Being}

We have argued that an important reason to measure quiet ego characteristics is because the development of these characteristics should promote well-being (Bauer and Wayment 2008). Our results found some indirect support for this assertion. The QES was associated positively with self-esteem, the ability to savor everyday experiences, life satisfaction, subjective well-being, psychological resilience, and the feeling that life is meaningful. This pattern of findings suggests that a quiet ego is not a squashed or silenced ego but rather an ego that balances both agency and communion (Bakan 1966), self-protection and growth goals (Schwartz et al. 2012). Indeed, the quiet ego appears to reflect both strength of and satisfaction with the self as an individual while simultaneously being given toward honesty and humility and toward deeper commitments to serving others and the environment. We did not find that the QES added much unique variance to a general measure of life satisfaction above and beyond related constructs like self-compassion, but this is not necessarily a negative finding. It simply suggests that that the skills and abilities associated with a quiet ego are those that promote growth and, ultimately, well-being.

\subsection{Conceptual Overlap with Related Constructs}

The QES was also associated positively and moderately with several established, multifaceted, psychological measures that we believed had one or more shared quiet ego characteristics: self-compassion, two measures of self-transcendence, authenticity, and the five-faceted mindfulness. Our set of studies provide preliminary evidence that the QES was 
associated with ecological identity, psychological resilience, coping efficacy, youth assets and psychological risk taking, controlling for related variables (not all at once) such as selftranscendence, self-esteem, authenticity, and five-facet mindfulness. These results suggest that our approach to capturing what four quiet ego characteristics have in common in the QES may be useful for researchers interested in the quiet ego as a construct. Future research will be needed to establish more conclusively the extent to which QES could add predictive validity to important real-world and behavioral outcomes (e.g., how one responds to the self and others during times of stress) and how it might compliment other contemporary research areas that explore related ideas to the ideas presented here including hypo-egoic processes (Leary et al. 2010), compassionate and self-image goals (Crocker and Canevello 2008), authenticity (Kernis and Goldman 2006), humility (Exline 2008; Kesebir 2014, on humility as an ego quieting construct; Tangney 2000), self-transcendence (Levenson et al. 2005; Reed 2003), and personal wisdom (Staudinger and Glueck 2011).

\subsection{Limitations and Future Directions}

Several limitations of our study results should be acknowledged. One of the study's strengths was the ability to replicate the scale structure in two separate samples of college students, and demonstrate convergent and practical validity to some degree. As reflecting a mid-level theory, the QES was designed to use as a total score and growth items were positively correlated with items representing the other three characteristics. Inclusive identity and perspective taking items were also consistently and positively correlated. However, there were some inconsistencies in the correlations between detached awareness and inclusive identity, somewhat weakening the reliability estimates. Nonetheless, in these cases, a quiet ego score would still reflect three of the four subscales and capture the essence of the quiet ego construct. However, if inclusive identity and detached awareness items were more strongly related the reliability estimates of the QES would be strengthened. We would argue that these are all ego-quieting characteristics, that the benefits of a compassionate self-identity may be more likely if all four are present, but there could also be great benefit if only one or two were at any given time. In study 3, the reliability for the QES was stronger among those higher in self-transcendence, suggesting that the scale's reliability may be influenced by factors related to an individuals experience with ego quieting thoughts and feelings.

Another limitation is that our hypotheses regarding the QES were tested in samples of university students of a traditional college age, and mostly female (especially in study 2), decreasing the generalizability of these findings. In five of six samples examined, the QES scores between men and women were not statistically significant, although the trend is that women's scores tend to be higher than men's scores. We believe that a closer examination of gender differences is warranted. For example, it may be that reductions in egoistic thoughts and feelings may express themselves differently and are influenced by sex roles and associated social norms.

Although our samples of college students included public college students, private college students, and first generation college students, there are other limitations that may arise when examining quiet ego characteristics in college students. Our reliance on college students may have imposed a limitation in variability and reliability of the measure. For example, the QES was moderately related and shared some important conceptual overlap with measures of self-transcendence, a characteristic that reflects a lessening of attachment to the self as one ages. Thus, the QES may have higher reliabilities in older adults. Based on Twenge's (2006) analysis of current young adults in the United States (the Millennial 
Generation, which she portrays as "Generation Me"), our samples of college students may have been more likely to demonstrate a particularly restricted and lower range of quiet ego characteristics, as they are characterized by cohort displaying increased individualistic and narcissistic traits than Baby Boomers (conversely, the possibility exists that the Baby Boomers mark a restricted range on the high side of generations across the century). Importantly for the study of the quiet ego, other analyses have demonstrated that age differences outweigh any generational differences in narcissism: People of any generation are more narcissistic in their youth but get less narcissistic with age (Roberts et al. 2010). Furthermore, the period of emerging adulthood (roughly ages 18 to the mid-20s) serves as a period of extended self-focus in contemporary industrialized nations, allowing individuals sufficient time to make sense of a complex society and to figure out their individual path through it (Arnett 2000). Indeed, the quiet ego is something that marks increasing levels of ego development (Bauer 2008). Given the nature of the quiet ego, and the potential that it comes with maturity, establishing the validity of the QES in older samples is an important next step.

Research on the benefits of developing a compassionate self-identity is steadily growing, especially in the context of how to develop resilience in the face of stresses and strains of every day life (Gilbert 2009). An important next step may be to explore ways in which individuals can be taught to cultivate quiet ego characteristics in their everyday lives, and experimentally examine whether such efforts (e.g., interventions, education) can impact individuals' overall psychological and physical well-being. In spite of the limitations of investigating quiet ego processes in college students, the college years nonetheless represent a significant life transition where the cultivation of quiet ego characteristics may increase resilience and well-being. In his compelling treatise of the purpose and value of a college education, Delblanco (2012) calls college "a place where young people fight out among and within themselves contending ideas of the meaningful life, and where they discover that self-interest need not be at odds with concern for one another" (p. 177). We would argue that Delbanco is referring to the importance of the development of a quieted ego.

\section{Conclusion}

Our goal with this set of studies was to assess our earlier conceptualization of the quiet ego as a compassionate self-identity (Bauer and Wayment 2008). Our theoretical model was confirmed and resulted in the creation of a 14-item scale using items from previously developed scales to represent four factors representing the broad themes of growth and balance, at whose intersection is the representation of a capacity or readiness for compassionate thoughts, feelings and behavior. The current research findings are encouraging and contribute to a growing interest among research psychologists in the psychological dimensions of compassion, well-being, and human flourishing. We hope that the addition of the QES will help psychologists continue in their work to uncover the benefits of cultivating a readiness to view the self- and others in a more even-handed and compassionate way.

Acknowledgments Special thanks to Martina Maris for her help with data collection (Study 2) and Taylor Fellbaum and Alanna Pugliese, and their mentors Drs. Michael Rader and Melissa Birkett for allowing us to analyze some of the data (Study 4) they collected as part of their REU research experience (NSF 1263396). Study 1 was part of the third author's masters' thesis at Northern Arizona University, under the supervision 
of the first author. We would also like to thank the anonymous reviewers for their valuable and appreciated insights and helpful suggestions during the review process.

Open Access This article is distributed under the terms of the Creative Commons Attribution License which permits any use, distribution, and reproduction in any medium, provided the original author(s) and the source are credited.

\section{Appendix}

\section{See Table 7.}

Table 7 Final Quiet Ego Scale (with 5-point response scale)

I think it is important to have new experiences that challenge how you think about yourself and the world I find myself doing things without paying much attention*

I feel a connection to all living things

Before criticizing somebody, I try to imagine how I would feel if I were in their place

For me, life has been a continuous process of learning, changing, and growth

I do jobs or tasks automatically, without being aware of what I'm doing*

I feel a connection with strangers

When I'm upset at someone, I usually try to put myself in his or her shoes for a while I have the sense that I have developed a lot as a person over time

I rush through activities without being really attentive to them*

I sometimes find it difficult to see things from another person's point of view*

I feel a connection to people of other races

I try to look at everybody's side of a disagreement before I make a decision

When I think about it, I haven't really improved much as a person over the years*

All items were assessed on a 5-point scale from 1 (strongly disagree) to 5 (strongly agree)

* Reverse-coded item

\section{References}

Ardelt, M. (2003). Empirical assessments of a three-dimensional wisdom scale. Research on Aging, 25, 275-324.

Arnett, J. A. (2000). Emerging adulthood: A theory of development from the late teens through the twenties. American Psychologist, 5, 469-480.

Aron, A., Aron, E. N., \& Smollan, D. (1992). Inclusion of other in the self scale and the structure of interpersonal closeness. Journal of Personality and Social Psychology, 63, 596-612.

Ashton, M. C., \& Lee, K. (2009). The HEXACO-60: A short measure of the major dimensions of personality. Journal of Personality Assessment, 91, 340-345.

Baer, R. A., Smith, G. T., Hopkins, J., Krietemeyer, J., \& Toney, L. (2006). Using self-report assessment methods to explore facets of mindfulness. Assessment, 13, 27-45.

Bakan, D. (1966). The duality of human existence. Isolation and communion in Western man. Boston, MA: Beacon Press.

Bartone, P. T. (2007). Test-retest reliability of the Dispositional Resilience Scale-15, a brief hardiness scale. Psychological Reports, 101, 943-944.

Batson, C. D. (2011). Altruism in humans. New York: Oxford University.

Bauer, J. J. (2008). How the ego quiets as it grows: Ego development, growth stories, and eudemonic personality development. In H. A. Wayment \& J. J. Bauer (Eds.), Transcending self-interest: Psychological explorations of the quiet ego (pp. 199-210). Washington, DC: American Psychological Association Books. 
Bauer, J. J., \& Bonanno, G. A. (2001). Doing and being well (for the most part): Adaptive patterns of narrative self-evaluation during bereavement. Journal of Personality, 69, 451-482.

Bauer, J. J., \& McAdams, D. P. (2010). Eudemonic growth: Narrative growth goals predict increases in ego development and subjective well-being three years later. Developmental Psychology, 46, 761-772.

Bauer, J. J., Park, S. W., Montoya, R. M., \& Wayment, H. A. (in press). Growth motivation toward two facets of eudemonic self-development. Journal of Happiness Studies.

Bauer, J. J., \& Wayment, H. A. (2008). The psychology of the quiet ego. In H. A. Wayment \& J. J. Bauer (Eds.), Transcending self-interest: Psychological explorations of the quiet ego (pp. 7-19). Washington, DC: American Psychological Association.

Bentler, P. M. (1995). EQS: Structural equations program manual. Los Angeles, CA: BMDP Statistical Software.

Bono, J. E., \& Judge, T. A. (2003). Core self-evaluations: A review of the trait and its role in job satisfaction and job performance. European Journal of Personality, 17, S5-S18.

Brown, K. W., \& Ryan, R. M. (2003). The benefits of being present: Mindfulness and its role in psychological well-being. Journal of Personality and Social Psychology, 84, 822-848.

Brown, K. W., Ryan, R. M., Creswell, J. D., \& Niemiec, C. P. (2008). Beyond me: Mindful responses to social threat. In H. A. Wayment \& J. J. Bauer (Eds.), Transcending self-interest: Psychological explorations of the quiet ego (pp. 75-84). Washington, DC: American Psychological Association.

Bryant, F. B. (2003). Savoring Beliefs Inventory (SBI): A scale for measuring beliefs about savouring. Journal of Mental Health, 12, 175-196.

Buss, A. H., \& Perry, M. P. (1992). The Aggression Questionnaire. Journal of Personality and Social Psychology, 63, 452-459.

Cambell, W. K., \& Buffardi, L. E. (2008). The lure of the noisy ego: Narcissism as a social trap. In H. A. Wayment \& J. J. Bauer (Eds.), Transcending self-interest: Psychological explorations of the quiet ego (pp. 23-32). Washington, DC: American Psychological Association.

Campbell, W. K., Bonacci, A. M., Shelton, J., Exline, J. J., \& Bushman, B. J. (2004). Psychological entitlement: Interpersonal consequences and validation of a self-report measure. Journal of Personality Assessment, 83, 29-45.

Cassell, E. J. (2002). Compassion. In C. R. Snyder \& S. J. Lopez (Eds.), Handbook of positive psychology (pp. 434-445). Oxford, England: Oxford University.

Chesney, M. A., Neilands, T. B., Chambers, D. B., Taylor, J. M., \& Folkman, S. (2006). A validity and reliability study of the coping self-efficacy scale. British Journal of Health Psychology, 11, 421-437.

Choi, I., Koo, M., \& Choi, J. A. (2007). Individual differences in analytic versus holistic thinking. Personality and Social Psychology Bulletin, 33, 691-705.

Cohen, J. (1992). A power primer. Psychological Bulletin, 112(1), 155-159.

Crocker, J., \& Canevello, A. (2008). Creating and undermining support in communal relationships: The role of compassionate and self-image goals. Journal of Personality and Social Psychology, 95, 555-575.

Csikszentmihalyi, M. (1993). The evolving self. New York: Harper Perennial.

Damon, W., \& Hart, D. (1988). Self-understanding in childhood and adolescence. Cambridge, England: Cambridge University.

Davis, M. H. (1983). Measuring individual differences in empathy: Evidence for a multidimensional approach. Journal of Personality and Social Psychology, 44, 113-126.

Deci, E. L., \& Ryan, R. M. (2000). The "what" and "why" of goal pursuits: Human needs and the selfdetermination of behavior. Psychological Inquiry, 11, 227-268.

Delblanco, A. (2012). College: What is was, is, and should be. NJ: Princeton University Press.

DeVellis, R. F. (2012). Scale development: Theory and applications (3rd ed.). Newbury Park, CA: SAGE Publications.

Diener, E., Emmons, R. A., Larsen, R. J., \& Griffin, S. (1985). The Satisfaction with Life Scale. Journal of Personality Assessment, 49, 71-75.

Diener, E., Lucas, R. E., \& Scollon, C. N. (2006). Beyond the hedonic treadmill: Revising the adaptation theory of well-being. American Psychologist, 61, 305-314.

Dunlap, R. E., Van Liere, K. D., Mertig, A. G., \& Jones, R. E. (2000). Measuring endorsement of the new ecological paradigm: A revised NEP scale. Journal of Social Issues, 56, 425-442.

Emmons, R. A., \& McCullough, (2004). The psychology of gratitude. New York: Oxford University.

Erikson, E. H. (1950). Childhood and society. New York: Norton.

Exline, J. J. (2008). Taming the wild ego: The challenge of humility. In H. A. Wayment \& J. J. Bauer (Eds.), Transcending self-interest: Psychological explorations of the quiet ego (pp. 53-62). Washington, DC: American Psychological Association.

Franken, R. E., Gibson, K. J., \& Rowland, G. L. (1992). Sensation seeking and the tendency to view the world as threatening. Personality and Individual Differences, 13, 31-38. 
Fredrickson, B. L. (2013). Updated thinking on positivity ratios. American Psychologist, 68, 814-822.

Freud, S. (1953). The standard edition of the complete psychological works of Sigmund Freud (J. Strachey, Ed., Trans.). London: Hogarth Press.

Gilbert, P. (2009). The compassionate mind. Oakland, CA: New Harbinger Publications Inc.

Gross, J. J., \& John, O. P. (2003). Individual differences in two emotion regulation processes: Implications for affect, relationships, and well-being. Journal of Personality and Social Psychology, 85, 348-362.

Haidt, J. (2012). The righteous mind: Why good people are divided by politics and religion. New York, NY: Random House.

Helgeson, V. S., \& Fritz, H. L. (1998). A theory of unmitigated communion. Personality and Social Psychology Review, 2, 173-183.

Hurley, A. E., Scandura, T. A., Schriesheim, C. A., Brannick, M. T., Seers, A., Vandenberg, R. J., et al. (1997). Exploratory and confirmatory factor analysis: Guidelines, issues, and alternatives. Journal of Organizational Behavior, 18, 667-683.

Huta, V., \& Ryan, R. M. (2010). Pursuing pleasure or virtue: The differential and overlapping well-being benefits of hedonic and eudemonic motives. Journal of Happiness Studies, 11, 735-762.

Jack, D. C. (1991). Silencing the self: Women and depression. Cambridge, MA: Harvard University.

James, W. (1890/1950). Principles of psychology. New York: Dover.

James, W. (1907 and 1909/1978). Pragmatism and the meaning of truth. Cambridge, MA: Harvard University.

Kasser, T. (2003). The high price of materialism. New York: Bradford.

Kasser, T., \& Ryan, R. M. (1993). A dark side of the American dream: Correlates of financial success as a central life aspiration. Journal of Personality and Social Psychology, 65, 410-422.

Kasser, T., \& Ryan, R. M. (1996). Further examining the American dream: Well-being correlates of intrinsic and extrinsic goals. Personality and Social Psychology Bulletin, 22, 281-288.

Kegan, R. (1982). The evolving self. Cambridge, MA: Harvard University.

Keltner, D. (2010). The compassionate instinct. In D. Keltner, J. Marsh, \& J. A. Smith (Eds.), The compassionate instinct (pp. 8-16). New York: Norton.

Kernis, M. H., \& Goldman, B. M. (2006). A multicomponent conceptualization of authenticity: Theory and research. In M. P. Zanna (Ed.), Advances in experimental social psychology (pp. 284-357). San Diego: Elsevier Academic Press.

Kesebir, P. (2014). A quiet ego quiets death anxiety: Humility as an existential anxiety buffer. Journal of Personality and Social Psychology, 106, 610-623. doi:10.1037/a0035814.

Leary, M. R. (2004). The curse of the self: Self-awareness, egotism, and the quality of life. Oxford, England: Oxford University.

Leary, M. R., Adams, C. E., \& Tate, E. B. (2010). Hypo-egoic self-regulation. In R. H. Hoyle (Ed.), Handbook of personality and self-regulation. New York: Guilford.

Leary, M. R., Tate, E. B., Adams, C. E., Allen, A. B., \& Hancock, J. (2007). Self-compassion and reactions to unpleasant self-relevant events: The implications of treating oneself kindly. Journal of Personality and Social Psychology, 92, 887-904.

Leary, M. R., Tipsord, J., \& Tate, E. B. (2008). Allo-inclusive identity: Incorporating the natural and social worlds into one's sense of self. In H. A. Wayment \& J. J. Bauer (Eds.), Transcending self-interest: Psychological explorations of the quiet ego (pp. 7-19). Washington, DC: American Psychological Association.

Levenson, M. R., Jennings, P. A., Aldwin, C. M., \& Shiraishi, R. W. (2005). Self-transcendence: Conceptualization and measurement. International Journal of Aging and Human Development, 60, 127-143.

Loevinger, J. (1976). Ego development. San Francisco: Jossey-Bass.

Lutz-Zois, C. J., Dixon, L. J., Smidt, A. M., Goodnight, J. A., Gordon, C. L., \& Ridings, L. E. (2013). An examination of gender differences in the construct validity of the silencing the self scale. Personality and Individual Differences, 55, 35-40.

Maslow, A. H. (1968). Toward a psychology of being. New York: Van Nostrand Reinhold.

McAdams, D. P. (2006). The redemptive self: Stories Americans live by. New York: Oxford University.

McAdams, D. P. (2008). Generativity, the redemptive self, and the problem of a noisy ego in American life. In H. A. Wayment \& J. J. Bauer (Eds.), Transcending self-interest: Psychological explorations of the quiet ego (pp. 235-242). Washington, DC: American Psychological Association.

McAdams, D. P., \& de St. Aubin, E. (1992). A theory of generativity and its assessment through self-report, behavioral acts, and narrative themes in autobiography. Journal of Personality and Social Psychology, 62, 1003-1015.

McAdams, D. P., \& Pals, J. L. (2006). A new big five: Fundamental principles for an integrative science of personality. American Psychologist, 61, 204-217. 
McCullough, M. E., \& vanOyen Witvliet, C. (2002). The psychology of forgiveness. In C. R. Snyder \& E. Wright (Eds.), Handbook of positive psychology (pp. 446-458). New York: Oxford University.

Montoya, R. M., \& Pittinsky, T. L. (2011). When increased group identification leads to outgroup liking and cooperation: The role of trust. Journal of Social Psychology, 151, 784-806.

Murray, H. A. (1938/2007). Explorations in personality. (Dan P. McAdams, Ed.). New York: Oxford University.

Neff, K. D. (2003). The development and validation of a scale to measure self-compassion. Self and Identity, 2, 223-250.

Oman, R. F., Vesely, S. K., McLeroy, K. R., Harris-Wyatt, V., Aspy, C. B., Rodine, S., et al. (2002). Reliability and validity of the Youth Asset Survey (YAS). Journal of Adolescent Health, 31, 247-255.

Peterson, C., \& Seligman, M. E. P. (2004). Character strengths and virtues: A handbook and classification. Oxford: Oxford University Press.

Piaget, J. (1970). Piaget's theory. In P. Mussen (Ed.), Carmichael's manual of child psychology (pp. 703-732). New York: John Wiley.

Reed, P. G. (2003). The theory of self-transcendence. In M. J. Smith \& P. R. Liehr (Eds.), Middle range theory for nursing (pp. 145-166). New York: Springer.

Roberts, B. W., Edmonds, G., \& Grijalva, E. (2010). It is Developmental Me, not Generation Me: Developmental changes are more important than generational changes in narcissism-commentary on Trzesniewski \& Donnellan (2010). Perspectives on Psychological Science, 5, 97-102.

Robitschek, C. (1998). Personal growth initiative: The construct and its measure. Measurement and Evaluation in Counseling and Development, 30, 183-198.

Rogers, C. R. (1961). On becoming a person. Boston: Houghton Mifflin.

Rosenberg, M. (1965). Society and the adolescent self-image. Princeton, NJ: Princeton University Press.

Rusbult, C. E., \& Van Lange, P. A. M. (2002). Interdependence, interaction, and relationships. Annual Review of Psychology, 54, 351-375.

Ryan, R. M., \& Deci, E. L. (2001). On happiness and human potentials: A review of research on hedonic and eudemonic well-being. Annual Review of Psychology, 52, 141-166.

Ryff, C. D. (1989). Happiness is everything, or is it? Explorations on the meaning of psychological wellbeing. Journal of Personality and Social Psychology, 57, 1069-1081.

Ryff, C. D., \& Singer, B. (1998). The contours of positive human health. Psychological Inquiry, 9, 1-28.

Schwartz, S. H., Cieciuch, J., Vecchione, M., Davidov, E., Fischer, R., Beierlein, C., et al. (2012). Refining the theory of basic individual values. Journal of Personality and Social Psychology, 103, 663-688.

Sheldon, K. M. (1995). Creativity and self-determination in personality. Creativity Research Journal, 8 , 25-36.

Sheldon, K. M. (2004). Optimal human being: An integrated multi-level perspective. Mahwah, NJ: Lawrence Erlbaum.

Sprecher, S., \& Fehr, B. (2005). Compassionate love for close others and humanity. Journal of Social and Personal Relationships, 22, 629-651.

Staudinger, U. M., \& Glueck, J. (2011). Psychological wisdom research: Commonalities and differences in a growing field. Annual Review of Psychology, 62, 215-241.

Steger, M. F., Frazier, P., Oishi, S., \& Kaler, M. (2006). The Meaning in Life Questionnaire: Assessing the presence of and search for meaning in life. Journal of Counseling Psychology, 53, 80-93.

Tabachnick, B. G., \& Fidell, L. S. (2012). Using multivariate statistics. NJ: Pearson Publishing.

Tangney, J. P. (2000). Humility: Theoretical perspectives, empirical findings and directions for future research. Journal of Social and Clinical Psychology, 19, 70-82.

Thomashow, M. (1996). Ecological identity: Becoming a reflective environmentalist. Cambridge, MA: MIT Press.

Thurstone, L. L. (1947). The simple structure concept. Multiple factor analysis (pp. 319-346). Chicago: The University of Chicago Press, Ltd.

Twenge, J. M. (2006). Generation me: Why today's young Americans are more confident, assertive, entitled-and more miserable than ever before. New York: Free Press.

Vallacher, R. R., \& Wegner, D. M. (1987). What do people think they're doing? Action identification and human behavior. Psychological Review, 94, 3-15.

Verplanken, B., Friborg, O., Wang, C. E., Trafimow, D., \& Woolf, K. (2007). Mental habits: Metacognitive reflection on negative self-thinking. Journal of Personality and Social Psychology, 92, 526-541.

Waterman, A. S. (Ed.). (2013). The best within us: Positive psychology perspectives on eudemonic functioning. Washington, DC: American Psychological Association.

Watson, D., Clark, L. A., \& Tellegen, A. (1988). Development and validation of brief measures of positive and negative affect: The PANAS scales. Journal of Personality and Social Psychology, 54, 1063-1070. 
Wayment, H. A., \& Bauer, J. (2008). Transcending self-interest: Psychological explorations of the quiet ego. Washington, DC: American Psychological Association.

Wayment, H. A., \& O'Mara, E. M. (2008). The collective and compassionate consequences of downward social comparisons. In H. A. Wayment \& J. J. Bauer (Eds.), Transcending self-interest: Psychological explorations of the quiet ego (pp. 159-169). Washington, DC: American Psychological Association.

Wayment, H. A., \& Taylor, S. E. (1995). Self-evaluation processes: Motives, information use, and selfesteem. Journal of Personality, 63, 729-757.

Wayment, H. A., Wiist, B., Sullivan, B., \& Warren, M. (2011). Doing and being: The relationship of mindfulness and mindfulness meditation to Buddhist's psychological and physical health. Journal of Happiness Studies, 12, 575-589.

Worthington, R. L., \& Whittaker, T. A. (2006). Scale development research: A content analysis and recommendations for best practices. The Counseling Psychologist, 34, 806-838. 